\title{
RADIATION EFFECTS QUARTERLY PROGRESS REPORT FOR APRIL-JUNE 1954
}

North American Aviation, Inc.

\author{
Frank E. Faris
}

November 1,1954

Date Declassified:

December 6, 1955

Photostat Price $\$ \frac{9.30}{3.60}$
Microfilm Price $\$ \quad$ Available from the
Office of Technical Services
Department of Commerce
Washington 25, D. C.

Photostat Price \$
This report was prepared as a selentlflo account of Goveras ment-spone Com ment-sponsored work. Neither the United states, nothe commialon mission, nor any person ecting or Implted, wlth makes any warianty ur reprefuiness of the in. respect to the acct formation containeu mation, apparatu., may not infringe - The commission to the use of or from damades resulting from the use of, any information, apparasus, method, or process disclosed in this report.

Consolidation of this material into compact form to permit economical, direct reproduction has resulted in multiple folios for some pages e.g., 10-12, 27-29, etc。 


\section{DISCLAIMER}

This report was prepared as an account of work sponsored by an agency of the United States Government. Neither the United States Government nor any agency Thereof, nor any of their employees, makes any warranty, express or implied, or assumes any legal liability or responsibility for the accuracy, completeness, or usefulness of any information, apparatus, product, or process disclosed, or represents that its use would not infringe privately owned rights. Reference herein to any specific commercial product, process, or service by trade name, trademark, manufacturer, or otherwise does not necessarily constitute or imply its endorsement, recommendation, or favoring by the United States Government or any agency thereof. The views and opinions of authors expressed herein do not necessarily state or reflect those of the United States Government or any agency thereof. 


\section{DISCLAIMER}

Portions of this document may be illegible in electronic image products. Images are produced from the best available original document. 
2

THIS PAGE

WAS INTENTIONALLY

LEFT BLANK 


\section{TABLE OF CONTENTS}

Page No.

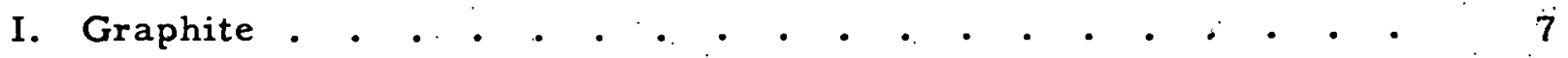

A. The Thermal Conductivity of Canadian Natural Graphite: . 7

B. The Theory of the Thermal Conductivity of Graphite . . . 14

C. Low Temperature Susceptibility. • • • • • . . . . $\quad 27$

D. Post-Irradiation Measurements of Cyclotron-Bombarded Graphite . • . . . . . . . . . . . . 30

E. In-Place $M$ ea surements of Cyclotron-Bombarded Graphite . $\quad 38$

F. Asymptotic Aging Experiments . . • • • • . • . . 38

II. Metals . • . . . . . . . . . . . . . . . . . . 43

A. Mechanism of Pore Formation Associated with the Kirkendall Effect . . . . . . . . . . . . . . 43

B. Annealing Studies of Cyclotron-Irradiated Thorium . . . 43

C. Tensile Properties of Iodide Thorium at Room Temperature and $77^{\circ} \mathrm{K}$. . . . . . . . . . . . . 46

D. Elastic Modulus : • . • • • • • • • • . • . • 47

E. Displacement Energy in Metals . : . . . . . . . . 48

F. Miscellaneous Low-Temperature Work • . • . . . . 48

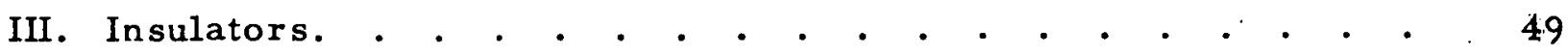

A. Mechanism of the Additive Coloring Reaction . . . . . 49

B. New Optical Effects in Additively Colored Crystals . . . 51

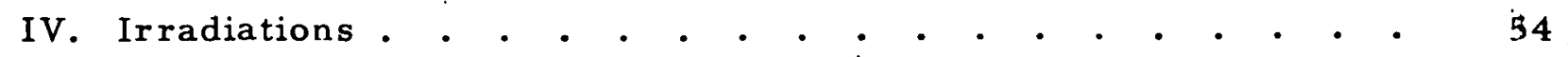

A. Cyclotron Operation and Development. • . . . . . . 54

B. Statitron Operation and Development • . . . . . . . 55

C. In-Pile Experiments . • . • . • • • . . • . • 56

References • • • • • • • • • • • • • • • • • • 57 . 57 


\section{LIST OF TABLES}

Page No.

I. Activation Energy for the Room-Temperature Annealing State in Thorium.

II. Tensile Properties.

\section{LIST OF FIGURES}

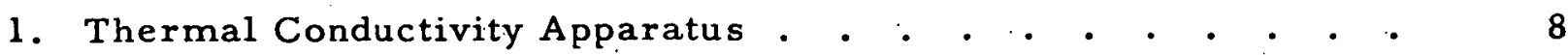

2. The Thermal Conductivitv of Natural Graphite Flakes ...$\quad 10$

3. Photograph of Surface of a Canadian Natural Graphite Sample . 11

4. Electrical Resistivity of a Canadian Natural Graphite.. . . . 13.

5. $\mathrm{T}^{3} / \mathrm{k}$ vs $\mathrm{T}$ for Different Pile Neutron Exposures for. Type AWG Graphite . . . • • • • • . . • • • • • • • 15

6. $\mathrm{T}^{3} / \mathrm{K}$ vs $\mathrm{T}$ for Different Pile Neutron Exposures for Type AGOT-KC Graphite . . . • . . • . • . . . . . . 16

7. $\mathrm{T}^{3} / \mathrm{K}$ vs $\mathrm{T}$ for Different Pile Neutron Exposures for Type SA-25 Graphite . . . . . . . . . . . . . . . . . 17

8. $T^{3} / k$ vs $T^{2}$ for Different Pile Neutron Exposures for Type

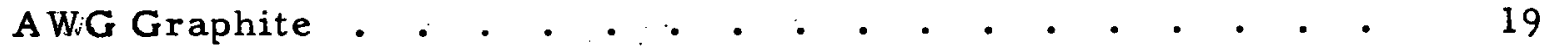

9. $\mathrm{T}^{3} / k$ vs $\mathrm{T}^{2}$ for Different Pile Neutron Exposures for Type AGOT-KC Graphite . . • • . • . . • • • • . • . 20

10. $\mathrm{T}^{3} / K$ vs $\mathrm{T}^{2}$ for Different Pile Neutron Exposures for Type SA-25 Graphite . . . . . . . . . . . . . . . . . 21

11. Internal Defects Introduced by Neutron Irradiation as a Function of Exposure . . . . . . . . . . . . . . . . - 23

12. $\mathrm{T}^{3} / \mathrm{k}$ vs $\mathrm{T}$ for Different Atom Ratios of $\mathrm{Br}$ in Type

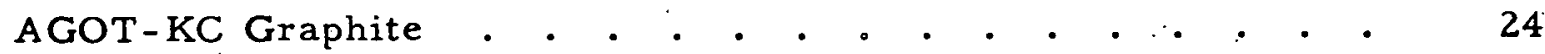

13. $\mathrm{T}^{3} / \kappa$ vs $\mathrm{T}^{2}$ for Different Atom Ratios of $\mathrm{Br}$ in $\mathrm{Type}$ AGOT-KC Graphite . . . . . . . • • . . • . . . 25

14. The Magnetic Susceptibility of Graphite as a Function of Exposure in a Cooled B Test Hole at Hanford Works . . . . 28

15. Dependence of Fermi Energy on Exposure . • • • • • • • 29 


\section{LIST OF FIGURES (Continued)}

Page No.

16. Apparatus for Measurement of Thermal Conductivity, Electrical Resistivity and Thermoelect ric Power of Graphite . . . '. . . 31

17. Arrangement of Apparatus in Dewar Flask . . . . . . . . . . . 32

18. Thermal Conductivity vs Temperature . . . . . . . . . . 34

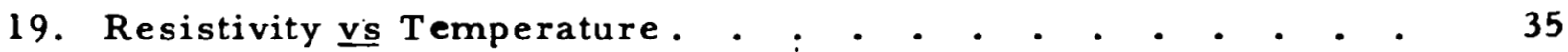

20. Thermoelectric Power vs Temperature . • . • . • • • • 36

21. Thermoelectric Power, Resistivity and Thermal Resistance

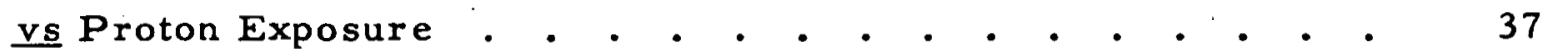

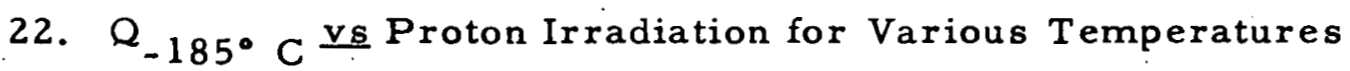

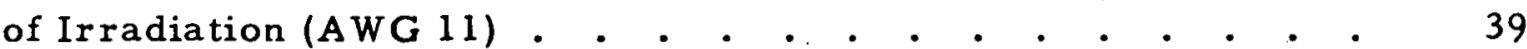

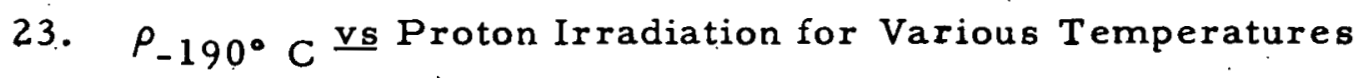

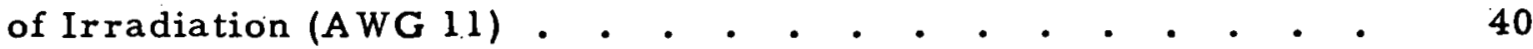

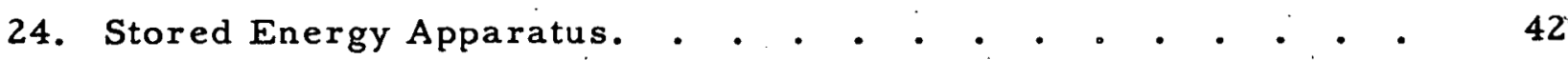

25. Absorption of $\mathrm{KCl}$ Colored in $\mathrm{Na}$ Vapor . . . . . . . . . . . . . 52

26. Absorption of Additively Colored KCl Containing Microscopically Observable Colloidal Particles . . . . . . 53 
THIS PAGE

WAS INTENTIONALLY

LEFT BLANK 


\section{*}

\section{GRAPHITE}

A. The Thermal Conductivity of Canadian Natural Graphite - A. W. Smith

The anomalous low temperature thermal conductivity of graphite samples measured previously has been explained by two different theories. The theory held by the group at this laboratory (Section I-B and Refs. 1 and ) is that a small amount of intergranular carbon contributes a $\mathrm{T}^{3}$ dependence to the conductivity. The intrinsic conductivity is held to be $\mathrm{T}^{2}$ dependent in the temperature region where boundary scattering predominates. Klemens ${ }^{3}$ holds that the anomalous conductivity is intrinsic to graphite and depends only on the ratio of the crystallite thickness to the crystallite width.

To help decide between these theories it seems very important to measure the thermal conductivity of a single crystal of graphite or a sample approaching this ideal. Since large single crystals are not available in this country an apparatus was constructed to measure small flakes of graphite. This apparatus is shown in Fig. 1. A small carbon resistor resting on bakelite legs was soldered to a heat meter consisting of a piece of AWG-type graphite, which has been measured on two different apparatus in this laboratory (Section I-D and Ref. 1. Between the AWG graphite and a copper block a flake of the graphite to be measured was placed. The ends were copper plated and soldered onto the block and to the AWG with Cerro-low-117 $\mathrm{F}$ solder. Differential thernocouples of 0.001 -inch chromel and constantan wire were cemented to both the AWG and the natural graphite samples. Tile reference junctions consisted of Teflon-covered 0.003 -inch copper wires which were brought through Cerro-low solder to obtain stable temperature control. An additional thermocouple with an ice reference junction was buried in the Cerro-low. Thus the temperatures of the reference junctions, the difference in the temperature between the graphite and the junctions, and the temperature gradients across the AWG and across the natural graphite were measured. The thermal conductivity was calculated from these data. The only heat leakage which could affect the results was through the 0.001 -inch wires and by radiation. These losses can be shown to be negligible. Samples of the order of $1 / 4$ inch by $1 / 20$ inch by $1 / 100$ inch have been measured in this way. To obtain temperature control this unit was

This report is based upon studies conducted for the Atomic Energy Commission under Contract AT-11-1-GEN-8. 


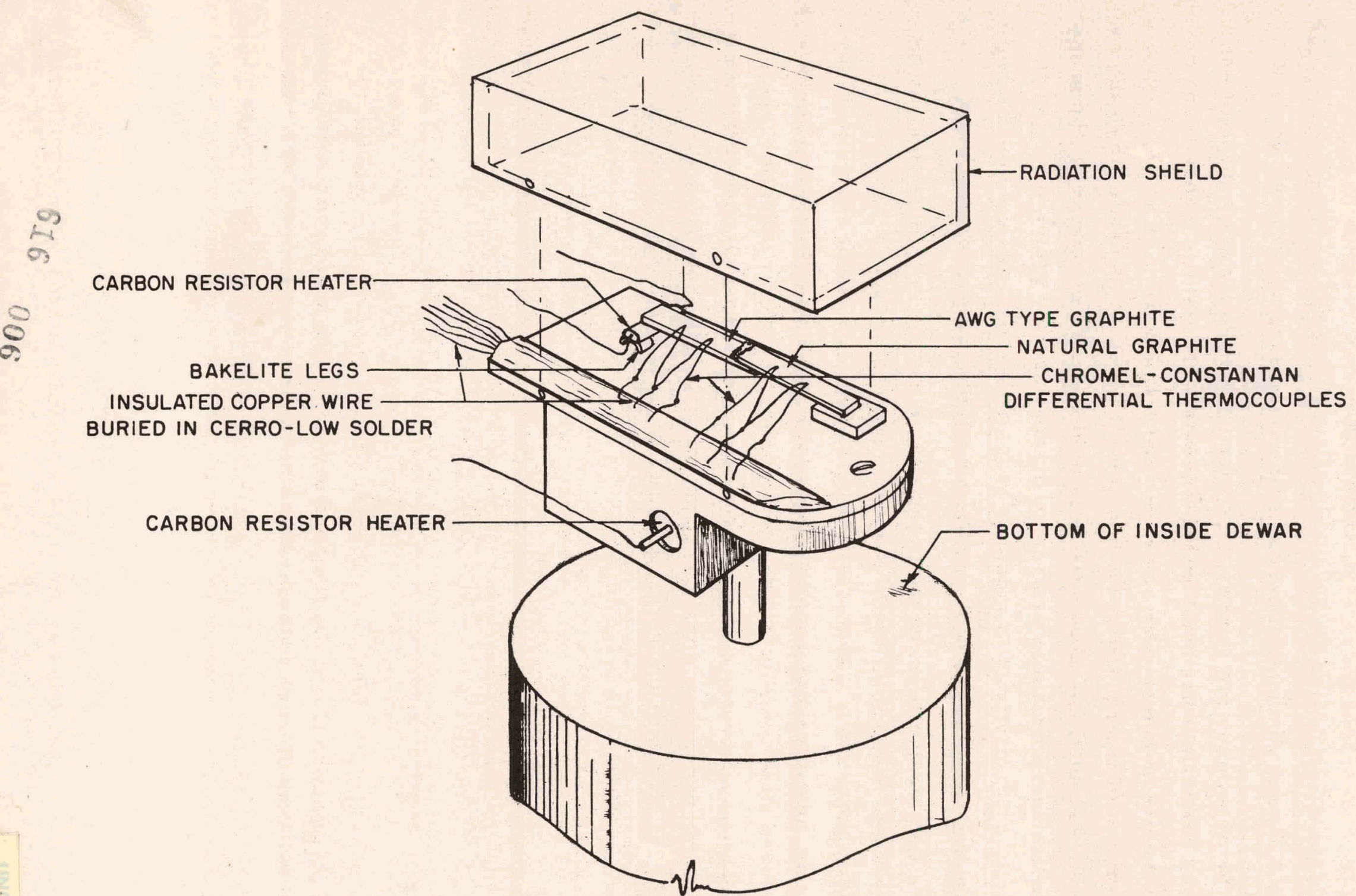

Fig. 1. Thermal Conductivity Apparatus 
connected to a copper.block with a 100-ohm carbon resistor heater and the block was connected to a dewar in the same fashion as in the apparatus discussed in Section I-D.

The results of the thermal conductivity measurements are shown in Fig. 2. The irregular nature of the flakes allows only a rough measure of the absolute value of the thermal conductivity to be made. The relative values at different temperatures are accurate to better than 10 per cent. The conductivity of all three samples at low temperatures varies as the second power of the absolute temperature.

The Canadian natural graphite used for these measurements was obtained from Dr. J. C. Bowman of the National Carbon Company. It has a lower ash content than most natural graphites. That it is not a single crystal can be seen by examining a magnified photograph of the surface of a typical flake in Fig. 3. Almost all of the lines crossing the surface lie at $120^{\circ}$ angles to each other and presumably represent distortion planes along the crystal axis. The average crystallite size determined from this photograph is of the order of $10^{-2} \mathrm{~cm}$.

A measurement of the mean-free path of thermal waves may be obtained from the temperature of maximum conductivity. An artificial graphite with crystallites estimated at $6 \times 10^{-5} \mathrm{~cm}$ has a maximum at about $300^{\circ} \mathrm{K}$ while this temperature is about $80^{\circ} \mathrm{K}$ for the Canadian natural graphite. If an Umklapp process is assumed to determine the conductivity above the maximum, and boundary scattering is assumed to limit the conductivity below this temperature, we can write the following equations:

For Umklapp scattering 4

$$
\mathrm{K}_{\mathrm{u}}=B \mathrm{~T}^{2} \mathrm{e}^{\theta / 2 \mathrm{~T}}
$$

for boundary scattering,

$$
\mathrm{K}_{\mathrm{B}}=\mathrm{A} \lambda \mathrm{T}^{2}
$$

and at the temperature of maximum conductivity,

$$
\mathrm{K}_{\mathrm{u}} \approx \mathrm{K}_{\mathrm{B}}
$$




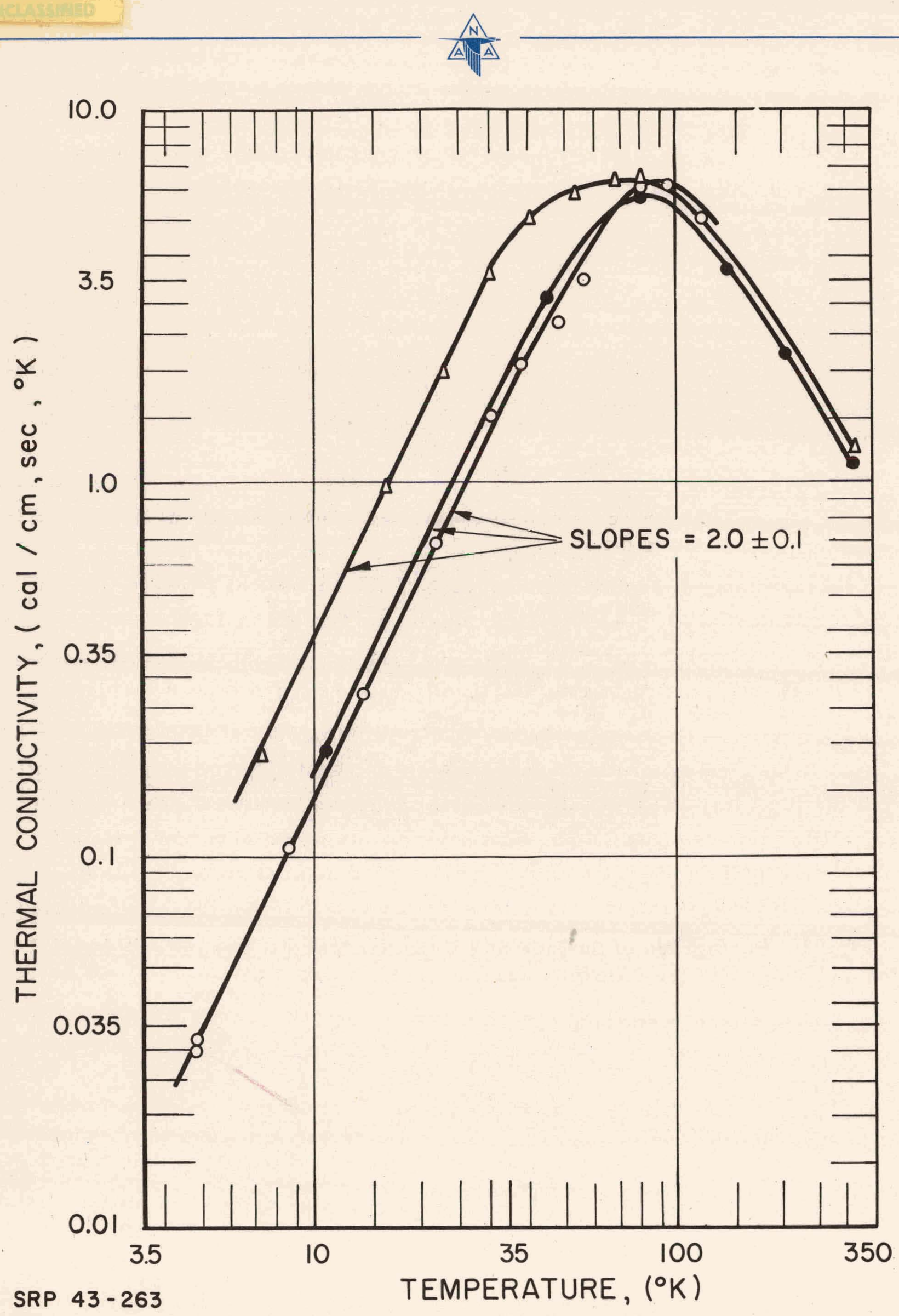

Fig. 2. The Thermal Conductivity of Natural Graphite Flakes 


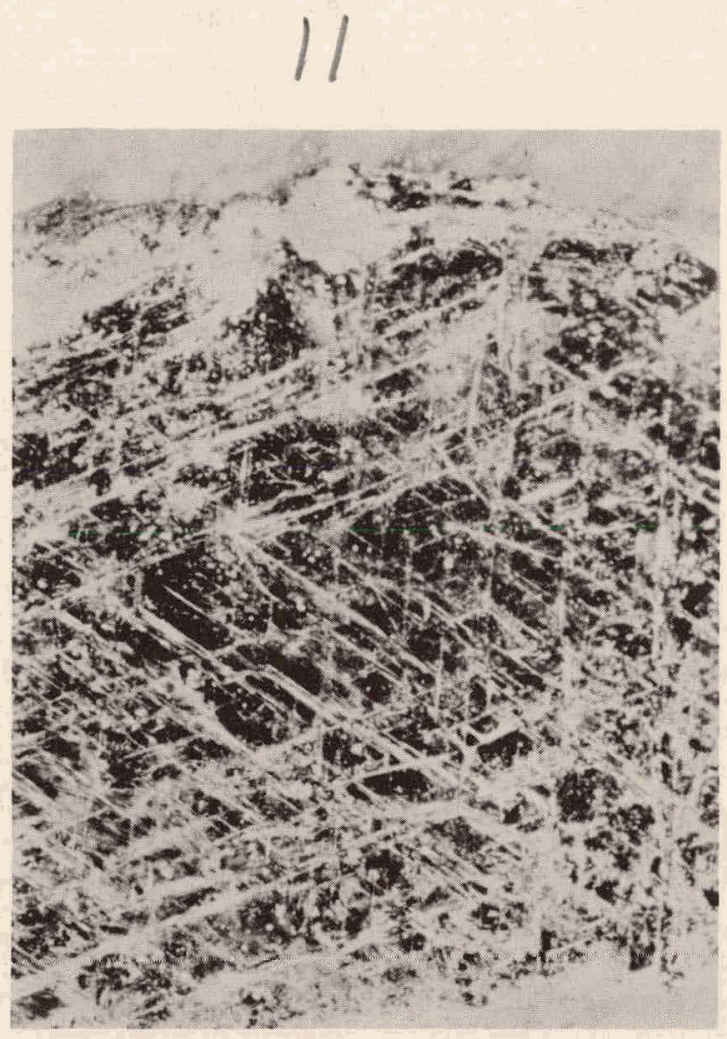

Fig. 3. Photograph of Surface of a Canadian Natural Graphite Sample<smiles>[C-]1[CH]C=C1</smiles> 
Then

$$
\theta=1000^{\circ} \mathrm{K}
$$

$$
\frac{\lambda_{1}}{\lambda_{2}} \approx \mathrm{e}^{\theta / 2\left(1 / \mathrm{T}_{1}-1 / \mathrm{T}_{2}\right)}
$$

$\mathrm{T}_{1}=$ temperature of maximum conductivity for artificial graphite $=300^{\circ} \mathrm{K}$

$\mathbf{T}_{2}=$ temperature of maximum conductivity for Canadian natural graphite $=80^{\circ} \mathrm{K}$

$\lambda_{1}=$ mean-free path for the artificial graphite $=6 \times 10^{-5} \mathrm{~cm}$

$\lambda_{2}=$ mean-free path for Canadian natural graphite $\approx 100 \lambda_{1} \approx 6 \times 10^{-3}$

The same result is obtained if the actual conductivities in the region of boundary scattering for the two samples are compared. Thus the mean-free path is the same as the crystallite size within the relatively crude approximations used in each case.

Figure 4 shows the electrical resistivity of a typical sample. The positive temperature coefficient is typical of single-crystal graphite ${ }^{5}$ in contrast to a negative coefficient found for artificial graphites as well as for a sample of Ceylon natural graphite measured at this laboratory. The nearly constant resistivity at higher temperatures is not found in single crystals. No explanation of this' constant value has been found except for the possibility that there are parallel conduction paths through very small crystallites.

Magnetic susceptibility measurements have been made on this material, and the total susceptibility has been found to be equal to the single crystal value in contrast to a value 5 to 10 per cent lower for the artificial graphites. The orientation factor is at least $20: 1$ in contrast to values of $1: 1$ to $2: 1$ for artificial graphites.

The conclusion reached is that the thermal conductivity of graphite at low temperatures has a $\mathrm{T}^{2}$ dependence and that the higher exponent previously found is to be explained by a two-medium theory. 


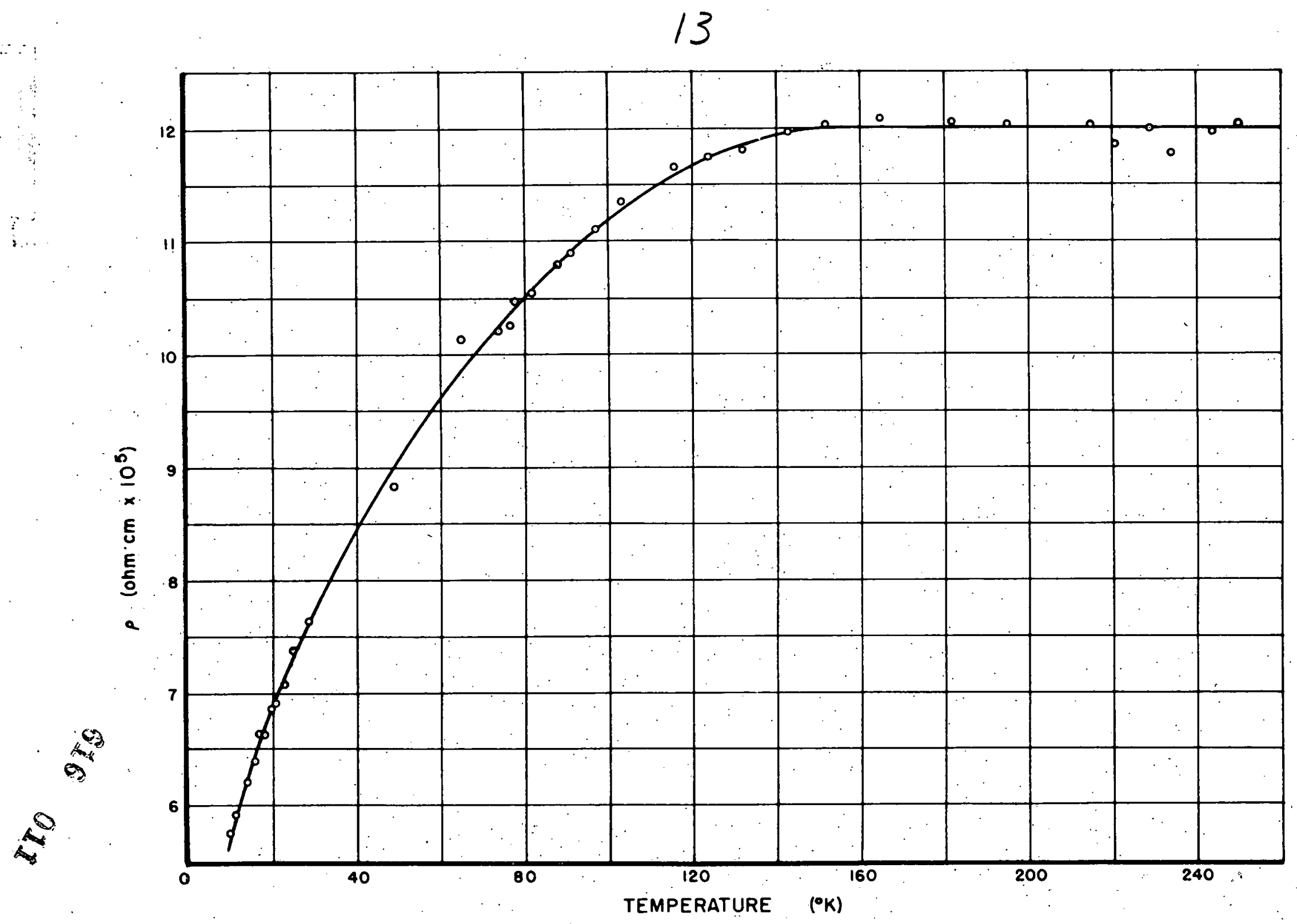


15

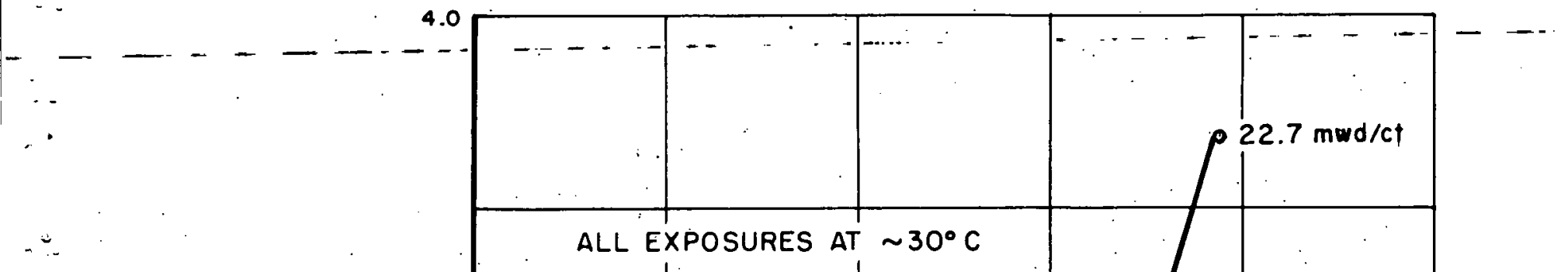

$\therefore$

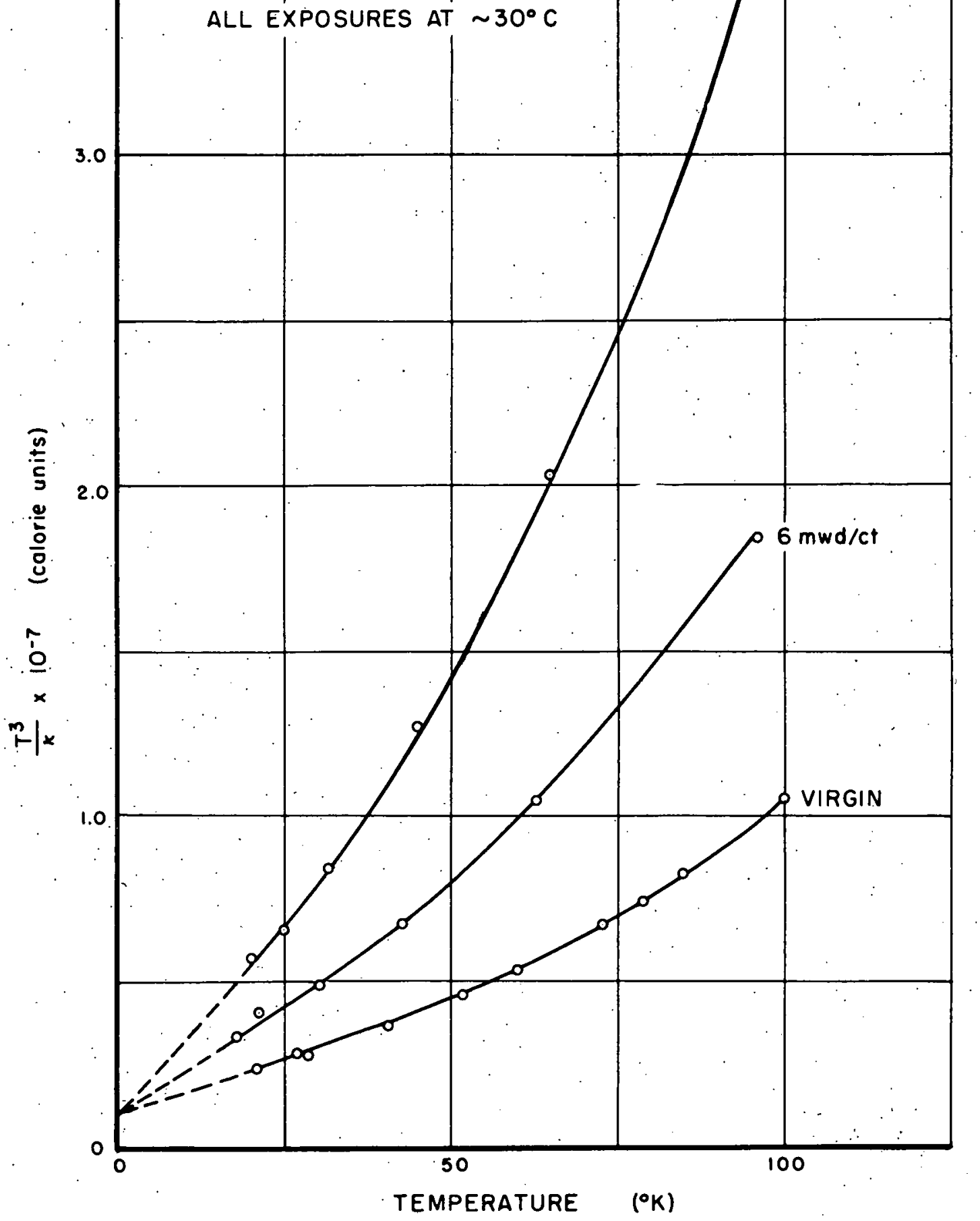

Fig. 5. $T^{3} / K$ vs $T$ for Different Pile Neutron Exposures for Type AWG Graphite 


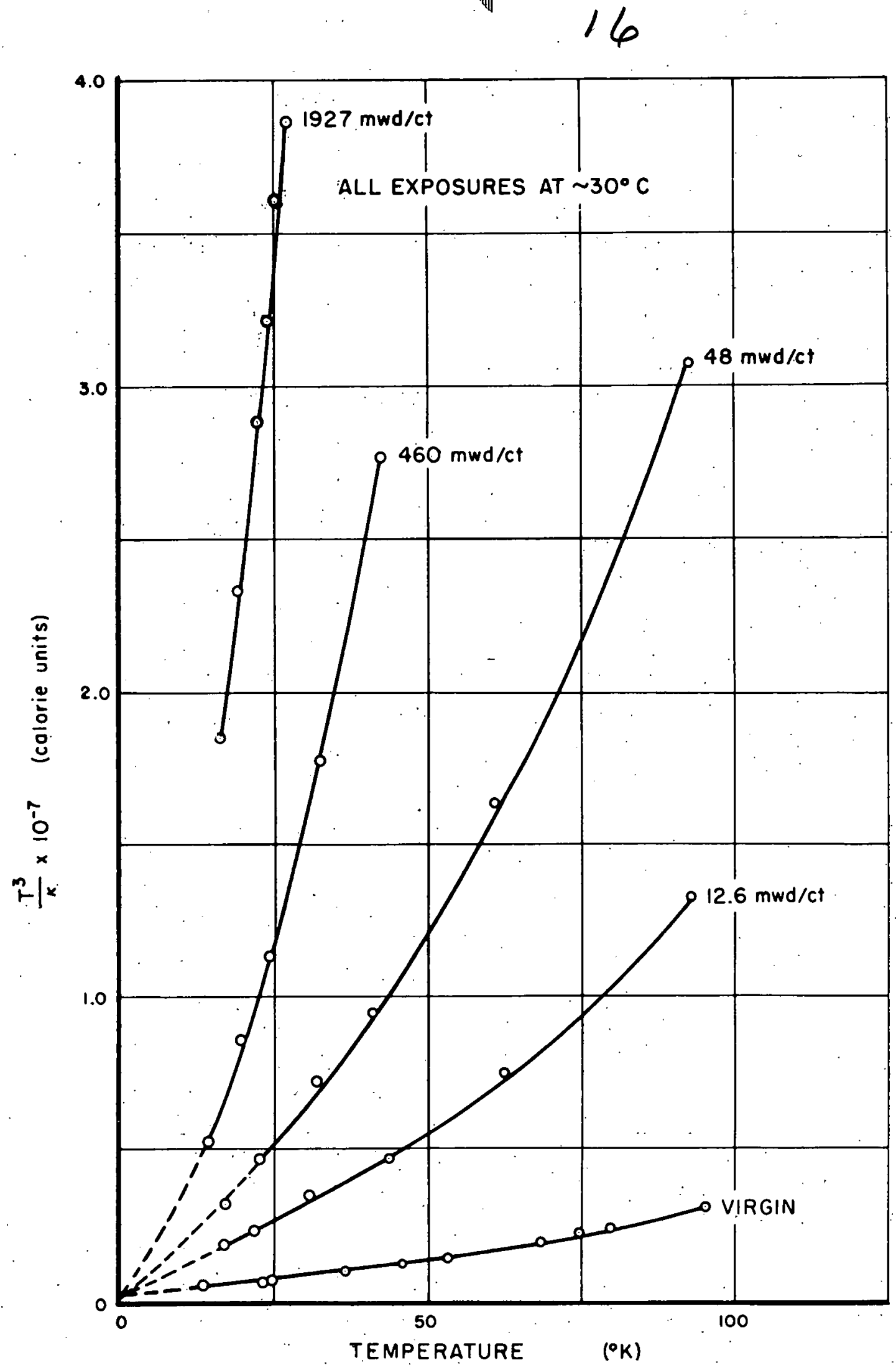

Fig. 6: $T^{3} / K$ vs $T$ for Different Pile Neutron Exposures for Type AGOT-KC Graphite 


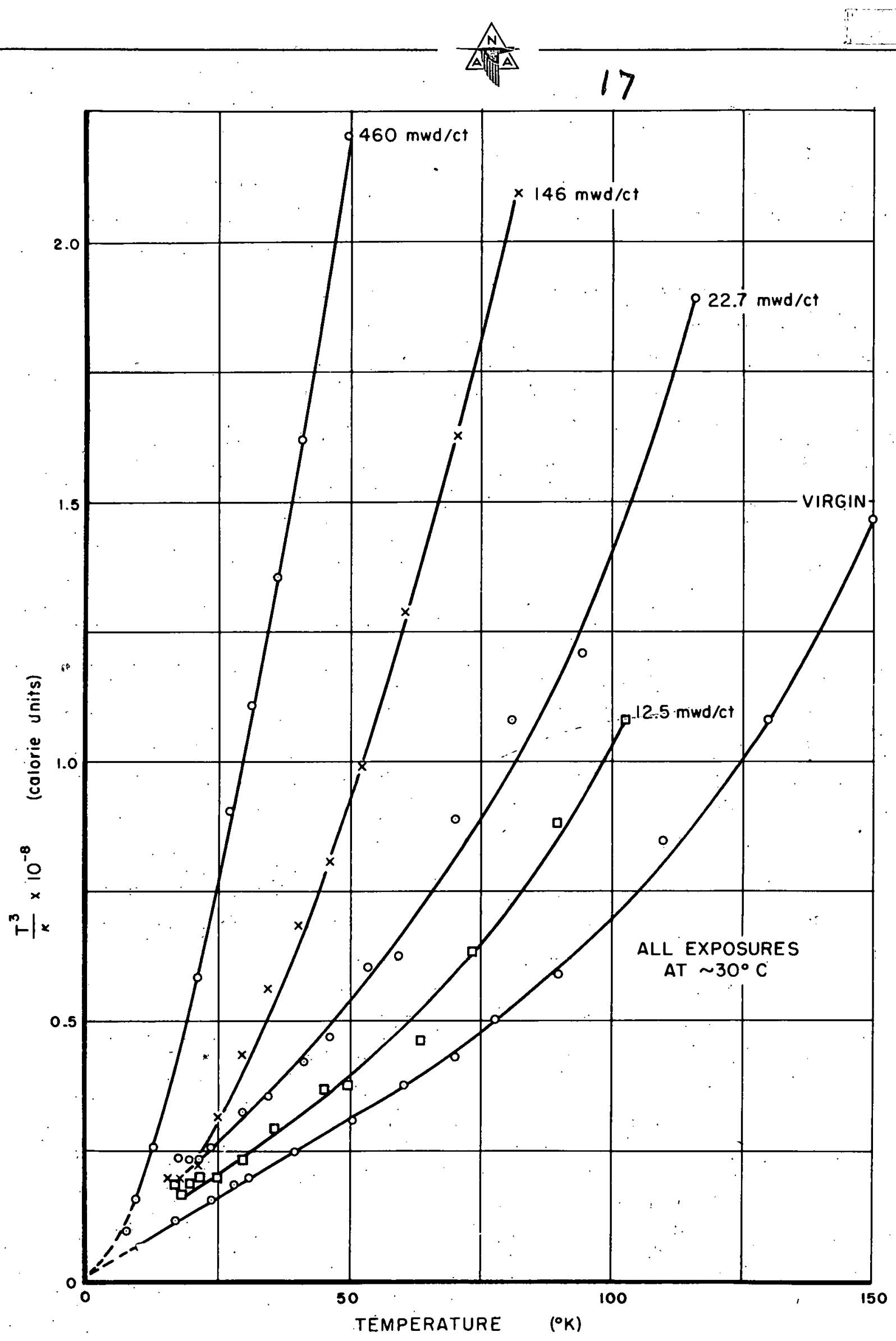

Fig. 7. $T^{3} / K$ vs $T$ for Different Pile Neutron Exposures for Type SA-25 Graphite

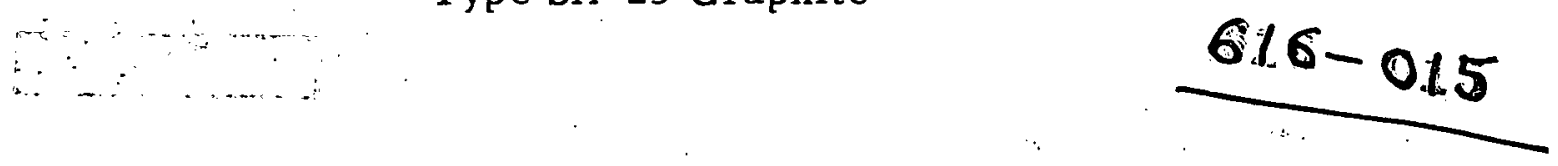


obtained from experimental data given previously for virgin and neutrondamaged AWG, AGOT $-K C$, and SA-25* graphite types. The behavior in the case of all three figures is consistent with the hypothesis that damage does little or nothing to affect the thermal properties of the non-graphitic region but does affect strongly the mean-free path, $\lambda_{2}$, in the crystallites. In every case that part of the curve deviating from a straight line is greatly increased in magnitude, but the $T=0$. intercept (defining $\lambda_{3}$ ) can, with reasonable accuracy, be drawn independent of damage. The most natural explanation of the curvature is that the graphite mean-free path is composed of two terms, one for boundary scattering and one for defect scattering, the latter being temperature dependent. Thus

$$
\frac{1}{\lambda_{2}}=\frac{1}{\ell_{\mathrm{b}}}+\frac{1}{\ell_{\mathrm{d}}(\mathrm{T})}
$$

In Figs. 8, 9, and 10 the quantity $\frac{T^{3}}{K}$ is plotted against $T^{2}$ and it is seen that the upper end of the curve becomes linear within the experimental error; thus it may be assumed that

$$
\ell_{\mathrm{d}}(\mathrm{T})=\text { constant } \mathrm{T}^{-1}
$$

Since the irradiation time greatly changes the constant in Eq. (3). (i.e., the constant is proportional to the slope in Figs. 8, 9, and 10), it is natural to consider one term in the constant as being the number of defects in the crystal; and, of course, it is by no means unreasonable to think that the unirradiated crystallites contain a certain number $\left(N_{0}\right)$ of defects which probably depends on the history of the specimen. Then Eq. (1) can be written

$$
\frac{\mathrm{T}^{3}}{\kappa}=\frac{\alpha \mathrm{T}}{\mathrm{s} \ell_{\mathrm{s}}}+\frac{\mathrm{NBT}}{\mathrm{s}}+\frac{60(1-\alpha)}{\lambda_{3}},
$$

where, to the present approximation, $B$ is independent of temperature and damage. Now $l_{b}$, the boundary scattering relaxation length, probably depends somewhat on damage also, but there is little hope of definitely separating this factor by use of the data presently available. For example, there are not enough

*It should be noted that the SA-25 curves are somewhat different from those given in Ref. The latter are incorrect due to a faulty thermocouple calibration. 


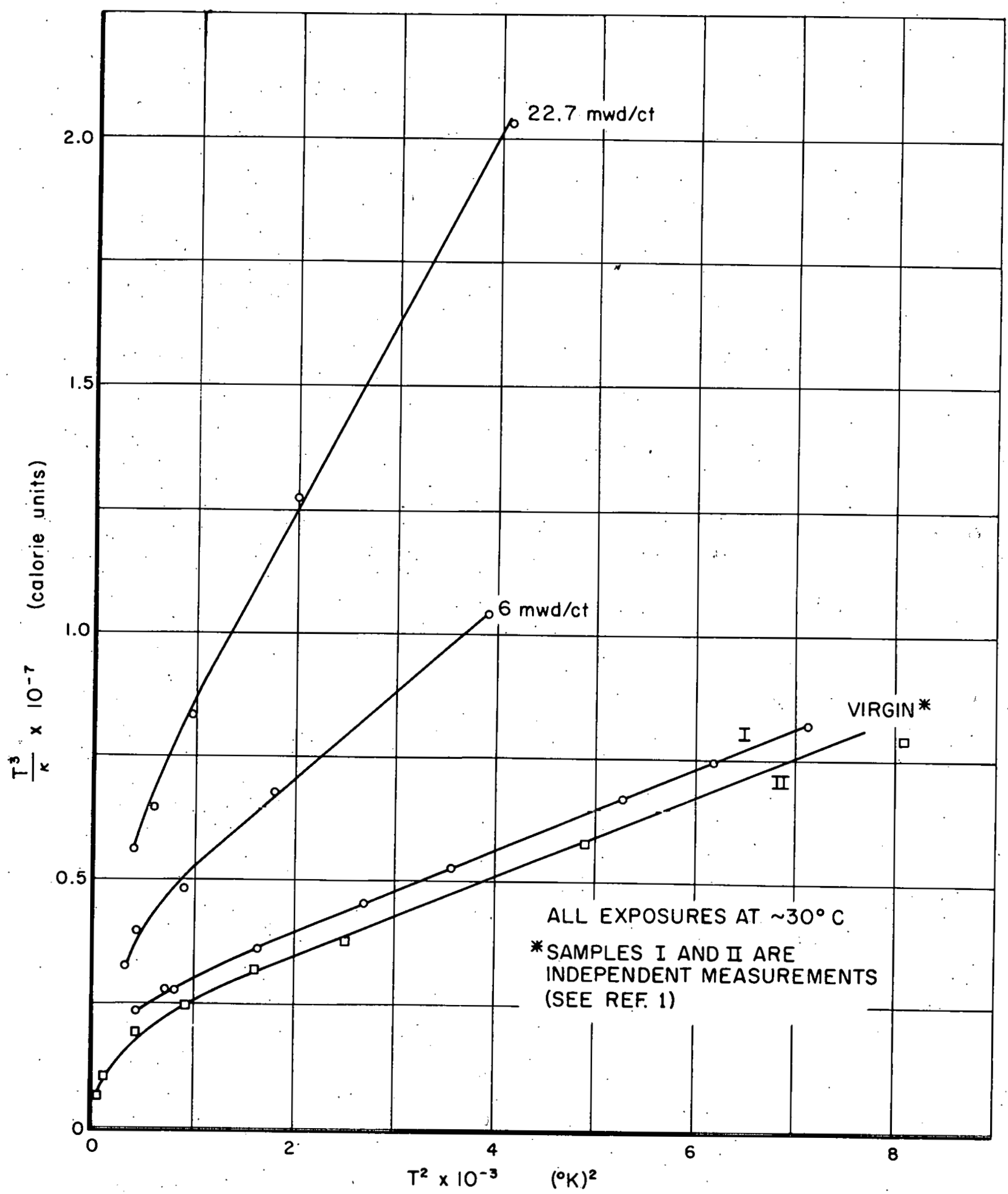

Fig. 8. $\mathrm{T}^{3} / \mathrm{k}$ vs $\mathrm{T}^{2}$ for Different Pile Neutron Exposures for Type AWG Grapinite 


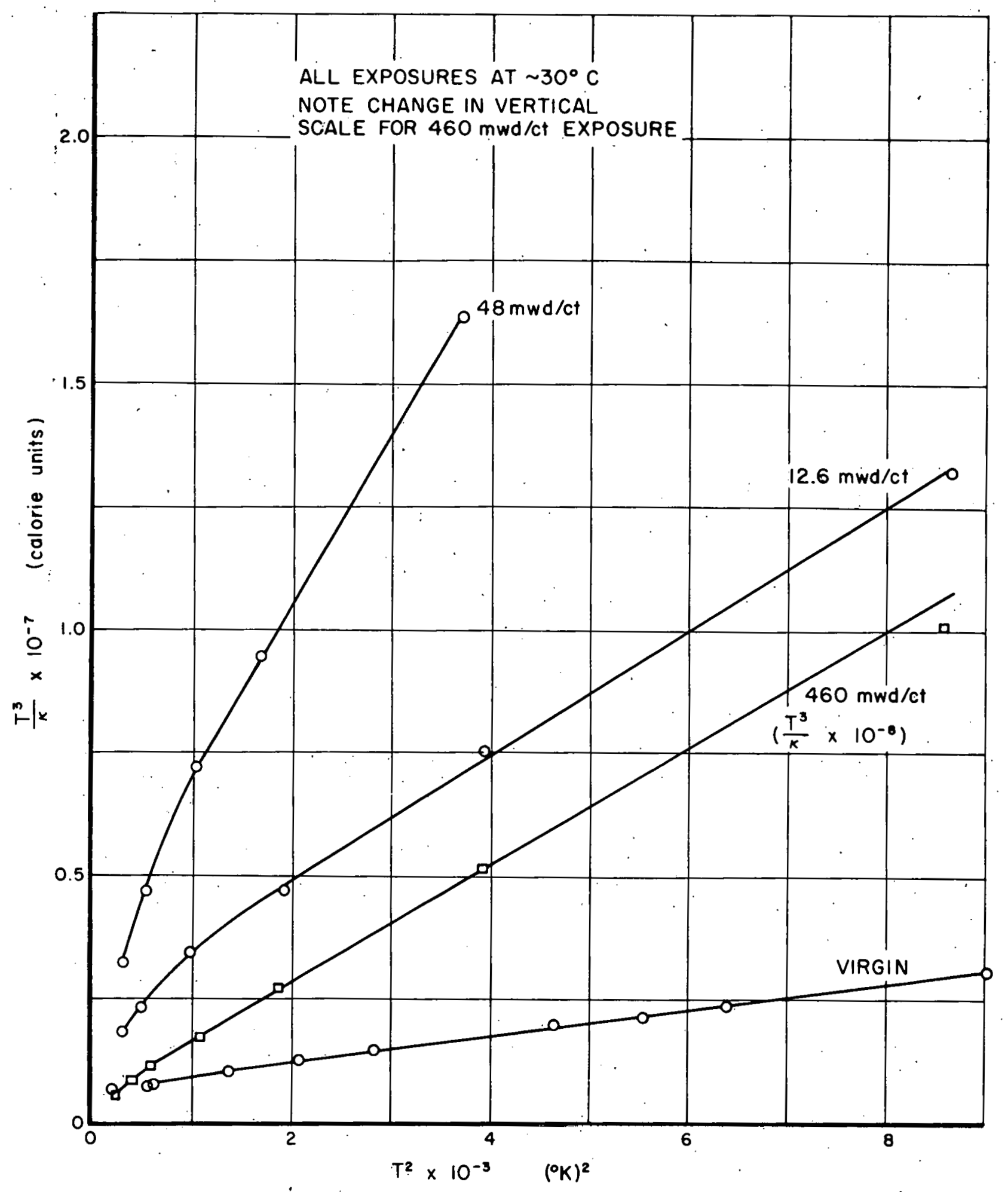

Fig. $9 \mathrm{~T}^{3} / \mathrm{k}$ vs $\mathrm{T}^{2}$ for Different Pile Neutron Exposures for Type AGOT-KC Graphite 
$\frac{A}{4 M^{2}}$

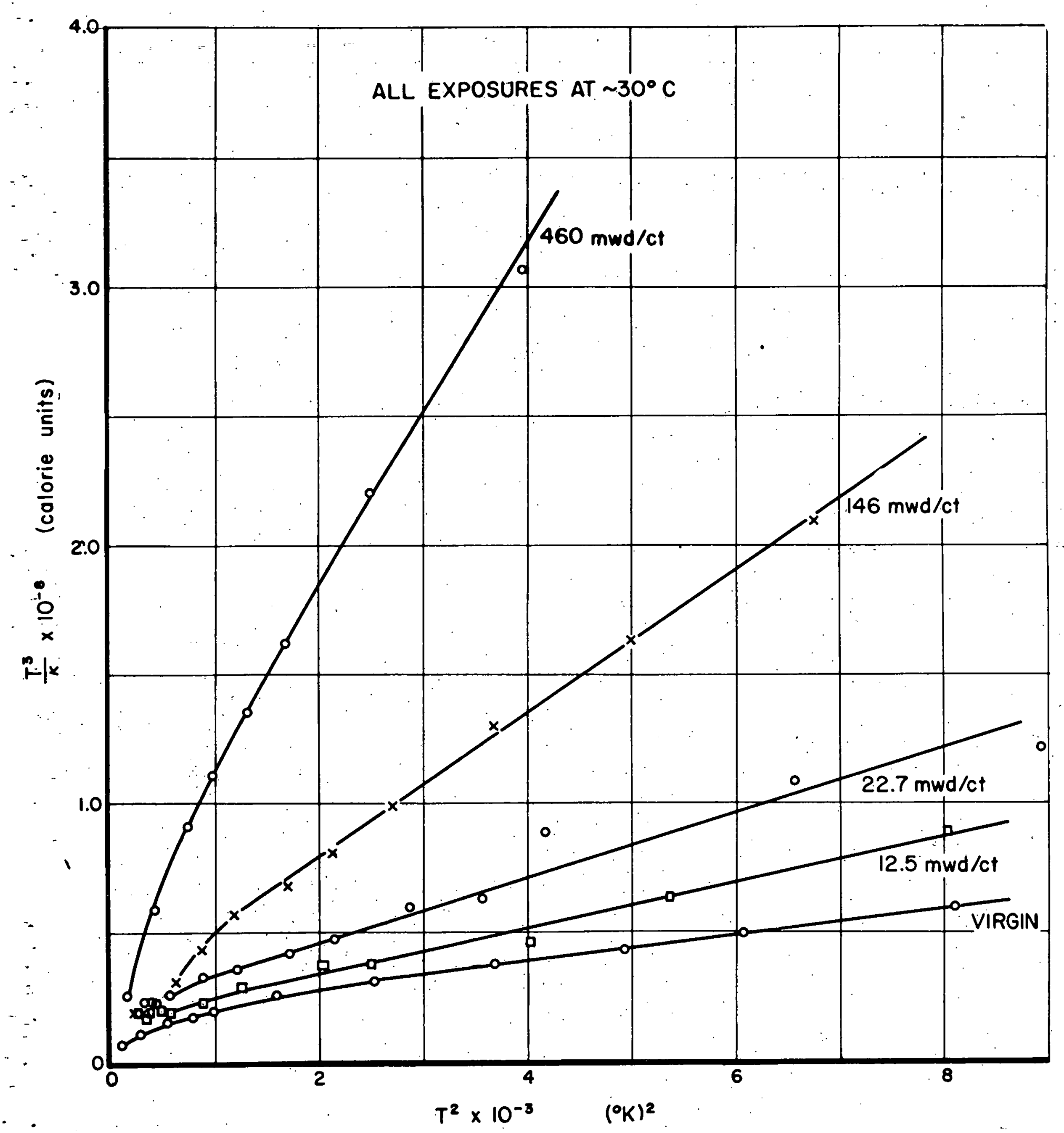

Fig. 10. $T^{3} / k$ vs $T^{2}$ for Different Pile Neutron Exposures for Type SA-25 Graphite

$$
\text { S18 } 019
$$


good low-temperature points in Figs. 5, 6, and 7 to be certain that the damage curves are in the linear region, although it is clear from Figs. 8, 9, and 10 that the lowest points are not in the quadratic region. On the other hand, the higher temperature data are not sufficiently precise to describe the slight curvature which would have to exist in Figs. 8, 9, and 10 if. Eq. (4) is correct and which would have to be known in order to obtain $\ell_{b}$ from the high-temperature data. It should be noted that if the damage affected only the linear term and not the quadratic term, a plot of $T^{3} / \kappa$ against $T^{2}$ would still show an apparent change in slope with damage. In the case of the brom-graphite compounds, which will be discussed later, it appears that the addition of small amounts of bromine does affect the linear term rather than the quadratic term; but it can be shown that neutron damage does not affect the linear term alone.

If, then, the middle term in Eq. (4) is taken as due to defects within the crystallites, the variation of the additional number of defects caused by neutron irradiation with exposure time can be obtained from the slopes in Figs. 8, 9, and 10. If estimated values of $a$, the volume fraction of graphitic material, and $s$, the orientation factor, are removed from the slopes, the factor $B\left(N-N_{0}\right)$ should be the same for all three graphite types. This factor is plotted against exposure time in Fig. 11. It may be seen that the correlation between different graphite types is not very good. There appears to be a crystallite size effect such that the smaller the crystallite size, the greater is the rate of producing internal defects. The reason for this difference is not known at present.

Some of the brom-graphite thermal conductivity data given in Ref. (i: have been used to obtain the curves of $\frac{T^{3}}{K}$ as given in Figs. 12 and 13 . It can be seen from Fig. 13 that the number of internal defect scatterers is not appreciably changed until about 1 per cent $B r$ is added. This value corresponds to the point where a lamellar compound is formed until this concentration is reached, it is presumed that the $B r$ congregates at boundaries and internal cracks. The presence of the ions at such locations would affect the boundary transmissivity and thus the boundary scattering path but not the internal defect scattering centers. The slight change in slope up to 0.884 per cent concentration in Fig. 13 can be mostly accounted for by the influence of the boundary term in Eq. (4). These conclusions are consistent with the results given in Ref. 7 , where the thermal resistance change with bromination is shown to deviate less from a $\mathrm{T}^{-2}$ behavior as the temperature is raised than does the neutron-damage change. 
i.

23
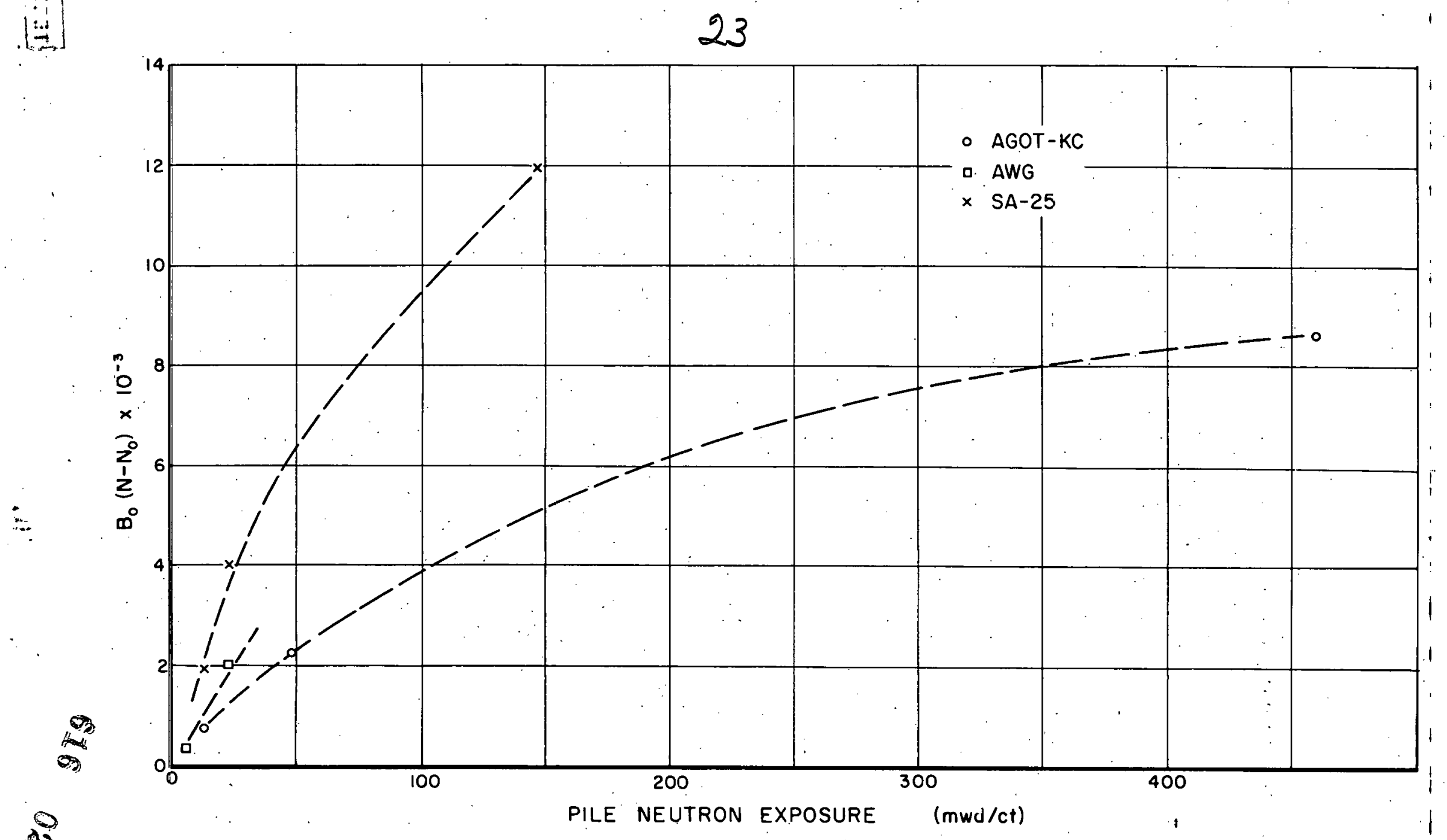

Fig. 11. Internal Defects Introduced by. Neutron Irradiation as a Function of Exposure 


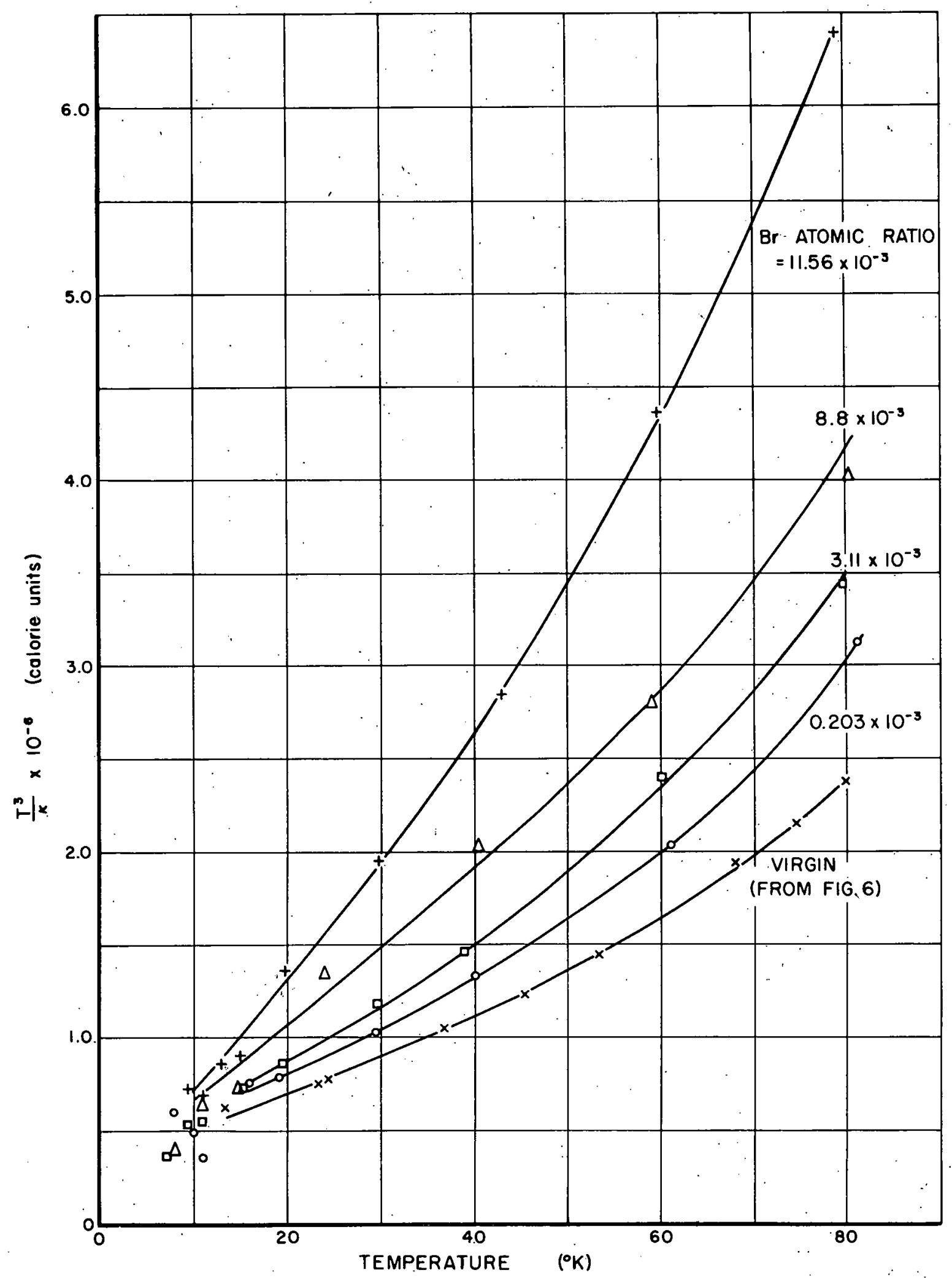

Fig. 12. $\mathrm{T}^{3} / K$ vs $\mathrm{T}$ for Different Atom Ratios of $\mathrm{Br}$ in Type A GOT-KC Graphite 


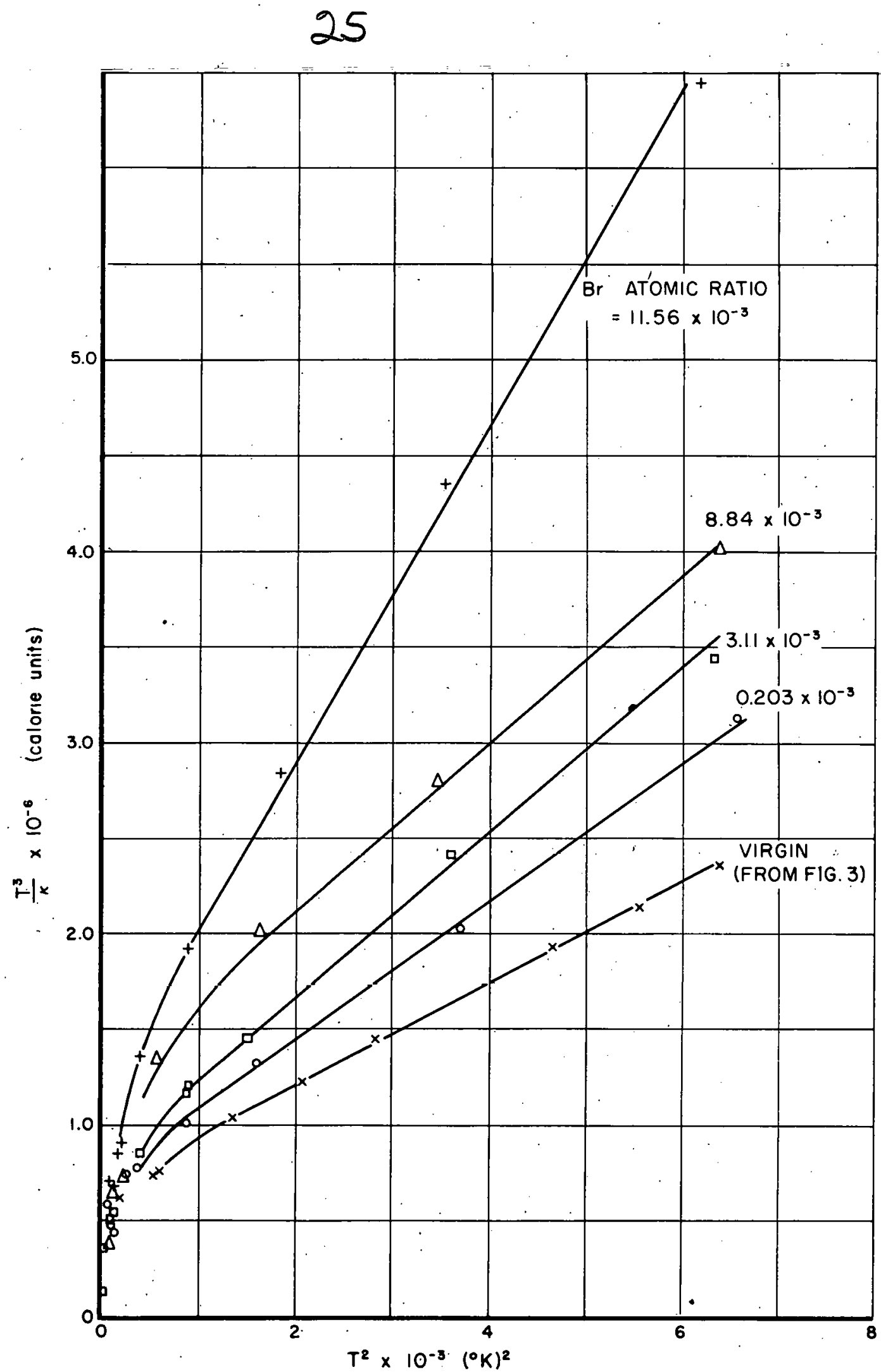

Fig. 13. $\mathrm{T}^{3} / K$ vs $\mathrm{T}^{2}$ for Different Atom Ratios of $\mathrm{Br}$ in Type AGOT-KC Graphite

896 

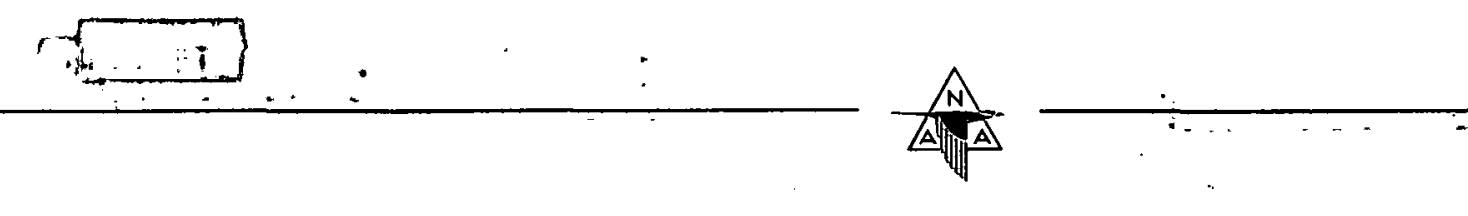

The phenomenological interpretation given above of the effect of damage . on the thermal conductivity of polycrystalline graphite is apparently consistent with all the known data; however, the picture cannot be considered completely

- satisfactory until a model has been formulated for the internal defects formed by neutron damage. While the detailed description of these defects has been una voidably vague in the above discussion, it appears that they must have a phonon scattering relaxation path which varies inversely as the phonon frequency, at least in the leading term for moderately low frequencies. The most obvious picture is to consider the defects as two-dimensional conglomerations of interstitials or vacancies whose effective size is a fair fraction of the waye length. If this model is correct, information concerning the size of these defects' can be obtained from scattering calculations in a two-dimensional elastic continuum. Such calculations are presently in progress:

2. Scattering of Phonons by Electrons - The calculation of the contribution of the conduction electrons in graphite to the thermal resistivity has been completed, and a topical report is being issued. Considering the phonon polarization to be divided into two in-plane modes and one out-of-plane mode, the only results not previously reported concern the out-of-plane modes. It is concluded that - insofar as electron scattering is concerned, these modes would be the most important ones. If $\Delta \zeta$ is the Fermi energy measured downward from the top of the filled band, it is found that

$$
\begin{array}{ll}
\kappa_{\mathrm{e}} \propto \mathrm{T} & (\Delta \zeta=0) \\
\kappa_{\mathrm{e}} \propto \frac{\mathrm{T}^{2}}{(\Delta \zeta)} & (2 \mathrm{kT}<\Delta \zeta<8, \mathrm{kT}) \\
\kappa_{\mathrm{e}} \propto \frac{\mathrm{T}^{2.5}}{(\Delta \zeta)^{1.5}} & (\Delta \zeta>8 \mathrm{kT})
\end{array}
$$

for low temperatures. The constants involve overlap integrals between nearest. and next-nearest neighbors in adjacent planes, and the limits on $\Delta \zeta$ are quite approximate. The most important point here is that the exponent of the tempera- ture increases as the damage (i.e., $\Delta \zeta$ ), in direct contradiction to the observed behavior of the experimental data. One may therefore conclude that electron scattering is probably not of importance in explaining the effects of neutron damage on the thermal conductivity. 


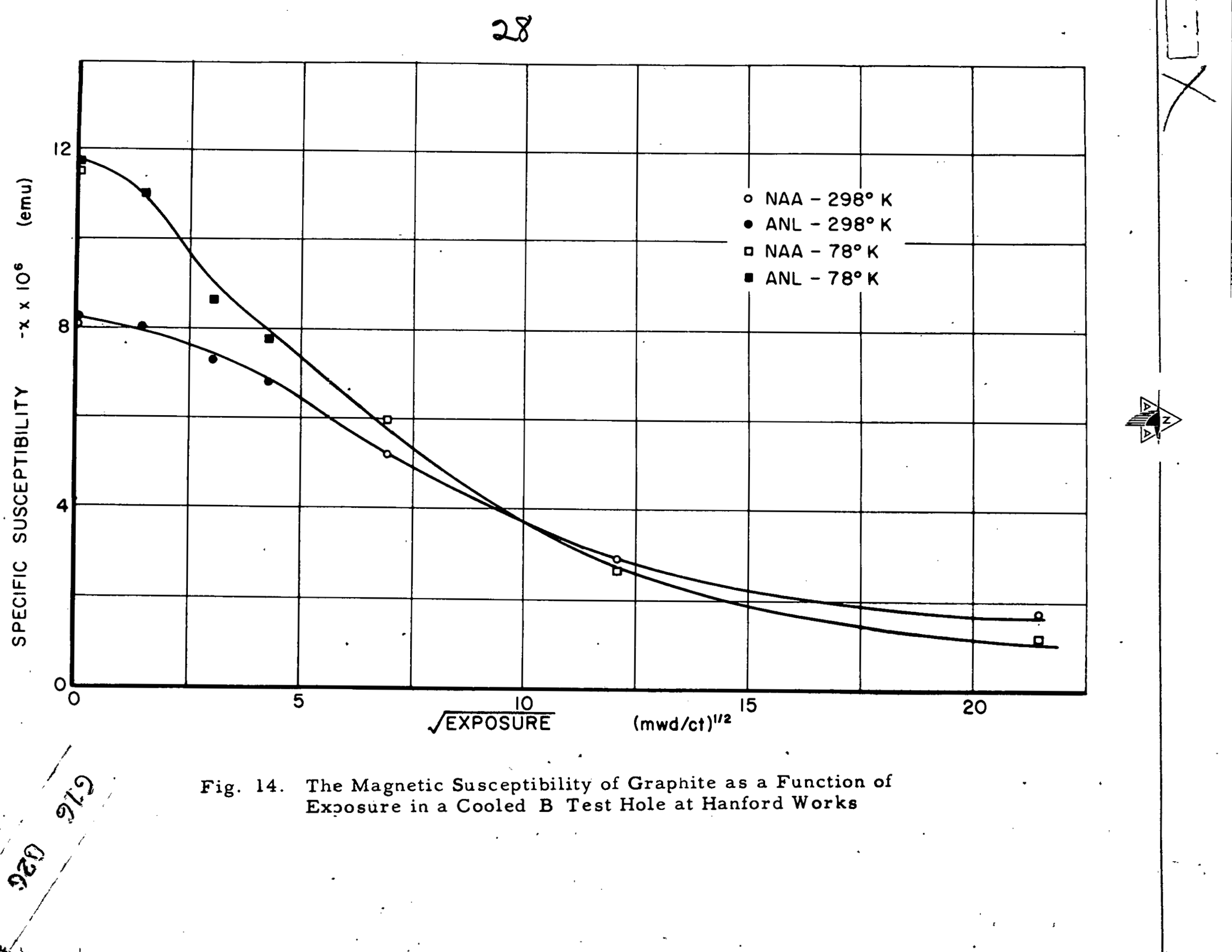




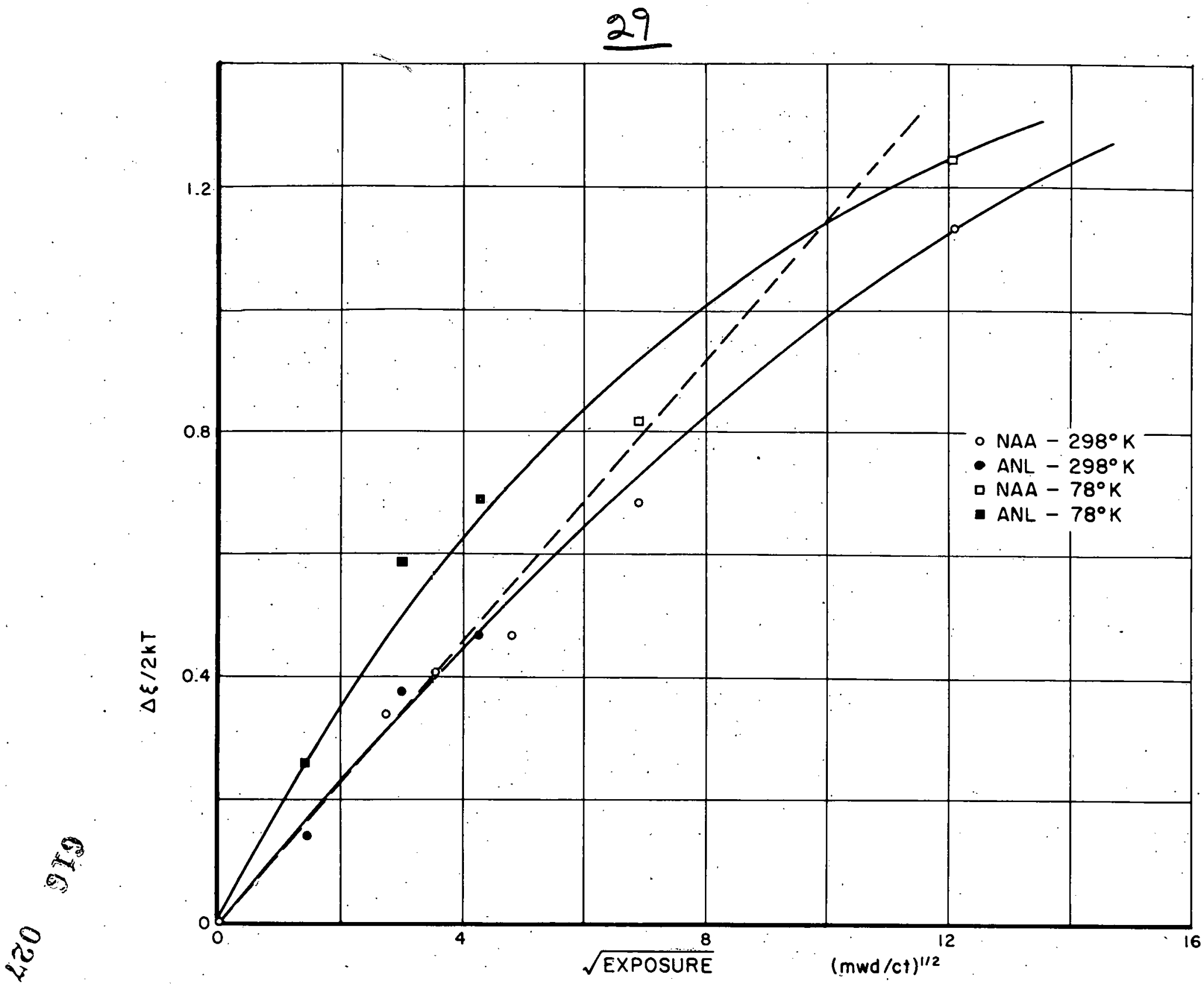

Fig. 15. Dependence of Fermi Energy on Exposure 
conclude therefore that the expression given for the susceptibility is not valid at liquid nitrogen temperatures.

It might be argued that this phenomenon is due to the presence of a number of complexes with unpaired spins, which would depress the low-temperature susceptibility of the irradiated graphite in some such a manner. However, the amount of such spin paramagnetism needed to account for the differences noted here is many times the value reported previously as an upper limit. It is believed that the failure of the low-temperature susceptibility to follow the behavior predicted by the theoretical expression arises from certain assumptions made in its derivation which are invalid at low temperatures.

D. Post-Irradiation Measurements of Cyclotron-Bombarded Graphite

\section{G. E. Deegan}

In connection with the experiments previously described sets of AWG graphite have been irradiated on the cyclotron in order to obtain more complete data for determining the nature of the damage produced by charged particles and in order to obtain information on the thermal annealing and the effect of the temperature of irradiation.

The apparatus used for the property determinations is shown in Fig. 16 and 17. The temperature dependence of the thermal conductivity, the electrical resistivity, and the thermoelectric power can be measured from $5^{\circ} \mathrm{K}$ to room temperature. In addition it is possible to use pulse annealing techniques to determine the changes produced by annealing in a sample irradiated at the liquidnitrogen temperature. The thermal conductivity is determined by passing a known current through the specimen and observing the temperature rise of its center by means of the 1 mil chromel-constantan couple shown in Fig. 16. The conductivity is then calculated by using the method of Smith and Rasor. The " thermoelectric power is determined by heating the specimen support blocks so that a differential temperature of approximately $8^{\circ} \mathrm{K}$ is maintained between them and reading the thermal emf between the two constantan legs of the end temperature thermocouples. These couples are butt-welded and pressed tightly against the sample by the specimen clamps. The value obtained is converted to the thermoelectric power relative to lead by means of a constantan-lead calibration. The electrical resistivity is obtained from the voltage drop between the tungsten probes inserted near the ends of the sample. 


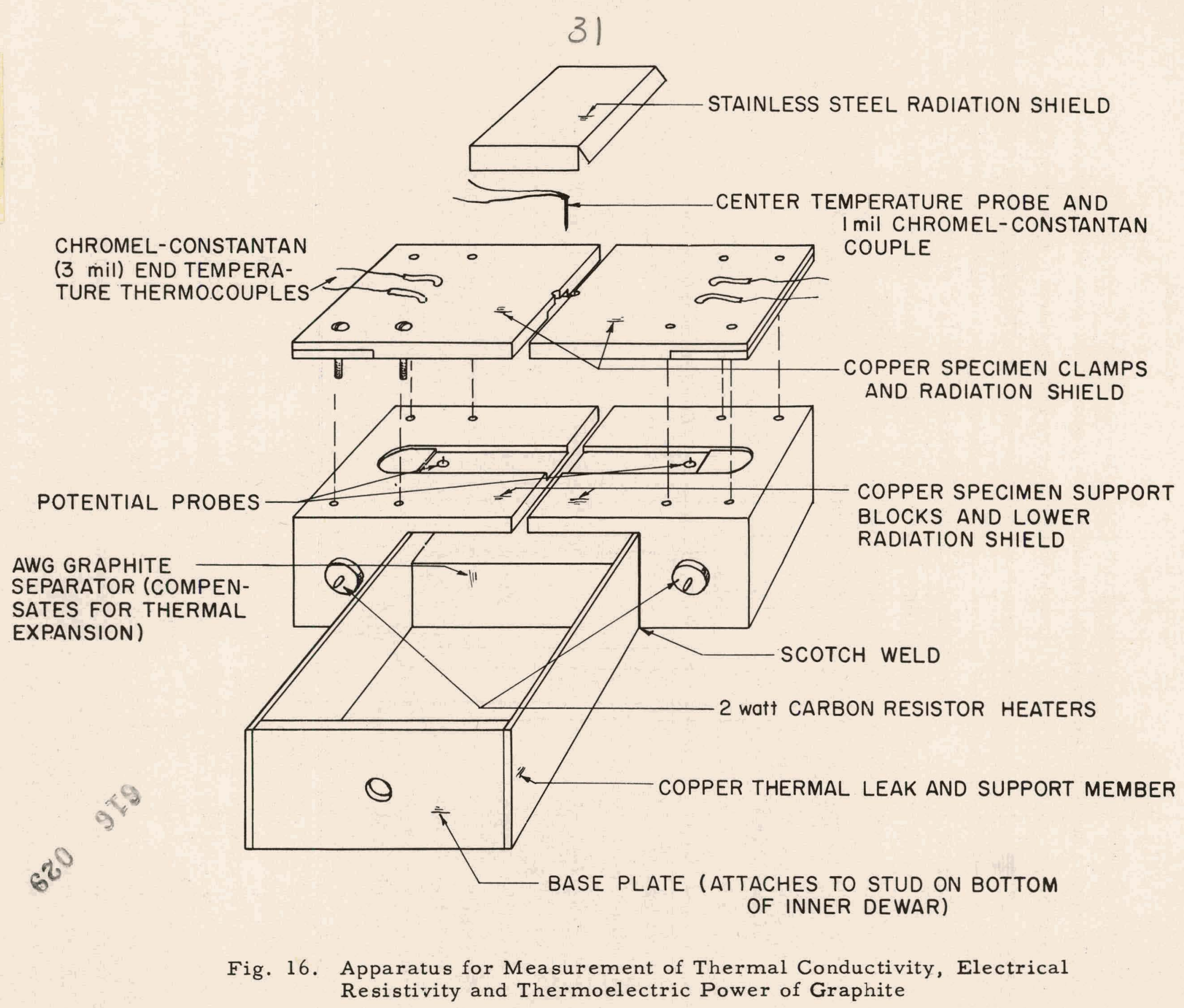


TO VACUUM SYSTEM

DOUBLE WALLED

GLASS DEWAR

LEAD WIRE

THERMAL CLAMP

KOVAR SEALS

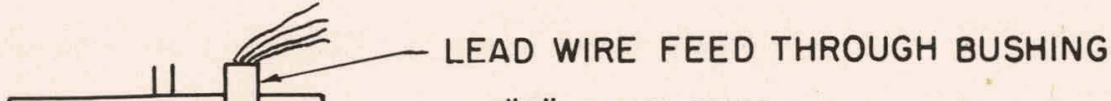
"O" RING SEAL

0.015 inch WALL STAINLESS STEEL

STAINLESS FILLING TUBE

LEAD WIRES

COPPER INNER DEWAR

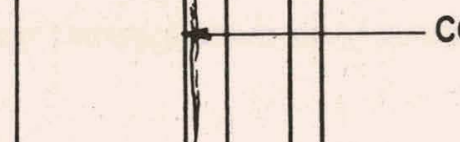

COPPER INNER DEWAR

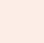


The thermal conductivity as a function of temperature is shown in Fig. 18. These data are similar to those obtained for neutron-irradiated graphite. At $90^{\circ} \mathrm{K}$ using the data reported by Smith and Rasor for $6 \mathrm{mwd} / \mathrm{ct}$ and $22.7 \mathrm{mwd} / \mathrm{ct}$ AWG samples one obtains an equivalence factor of $1 \mu \mathrm{amp}-\mathrm{hr} / \mathrm{cm}^{2}$ $\approx 1.4 \mathrm{mwd} / \mathrm{ct}$.

The change in the electrical resistivity (Fig. 19) is also quite similar to that caused by neutron irradiation. The factor relating the charged-particle bombardments to neutron irradiation is $1 \mu \mathrm{amp}-\mathrm{hr} / \mathrm{cm}^{2} \approx 1.3 \mathrm{mwd} / \mathrm{ct}$ at room temperature; moreover the factor is nearly independent of the temperature of mea surement.

The thermoelectric power (Fig. 20) shows a marked difference in temperature dependence from that observed for neutron-exposed samples. The maxima are higher if one compares the curves for cyclotron-bombarded samples with the curves for neutron-irradiated samples having the same thermoelectric power at $300^{\circ} \mathrm{K}$. It is possible to obtain some sort of equivalence factor at a given temperature; however, because of the noticeably different temperature dependence this factor would be completely meaningless at a nother temperature.

Figure 21 gives a plot of the three properties as a function of exposure at the temperatures indicated. The data for the thermoelectric power are in agreement with those obtained by W. S. Gilbert through in-place measurements (Section I-E). The scatter in the points for the thermal resistivity is approximately 5 per cent; which corresponds to the expected variation from sample to sample.

The exposures listed for these data are only approximate at the present time. An absolute flux determination is being made by counting the copper foils which were mounted in front of each specimen and will be available for the topical report covering the entire experiment.

At present there are on hand complete sets of graphite samples with similar exposures at temperatures of $90^{\circ} \mathrm{K}, 200^{\circ} \mathrm{K}, 300^{\circ} \mathrm{K}$, and $425^{\circ}$. $\mathrm{K}$. The properties of a number of the samples have been measured and will be reported when the results for an entire set at a given temperature are available.

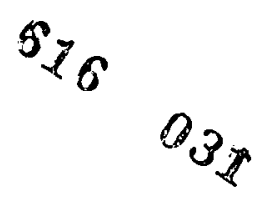


$-\frac{A}{A A}$

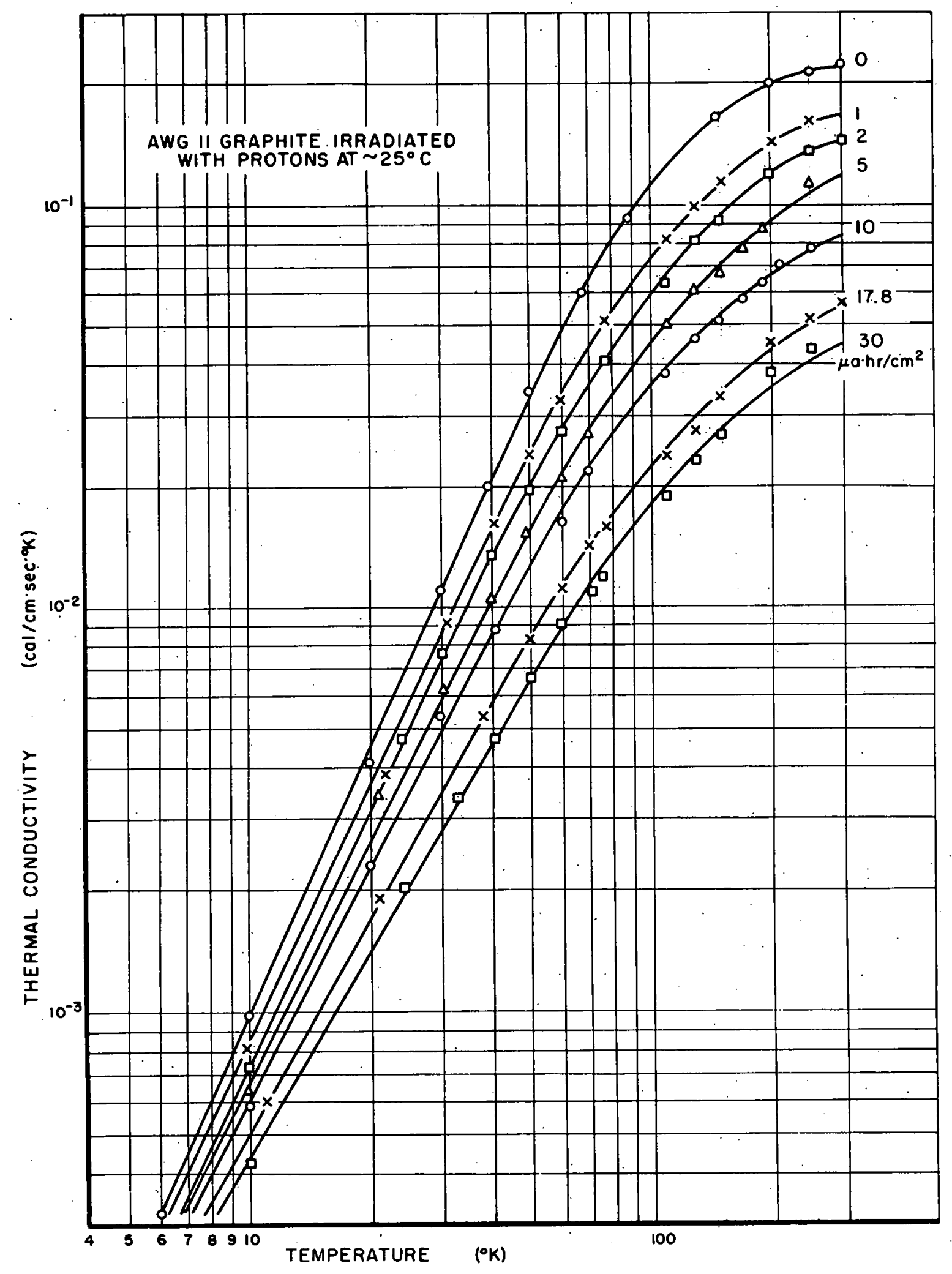

Fig. 18. Thermal Conductivity vs Temperature 


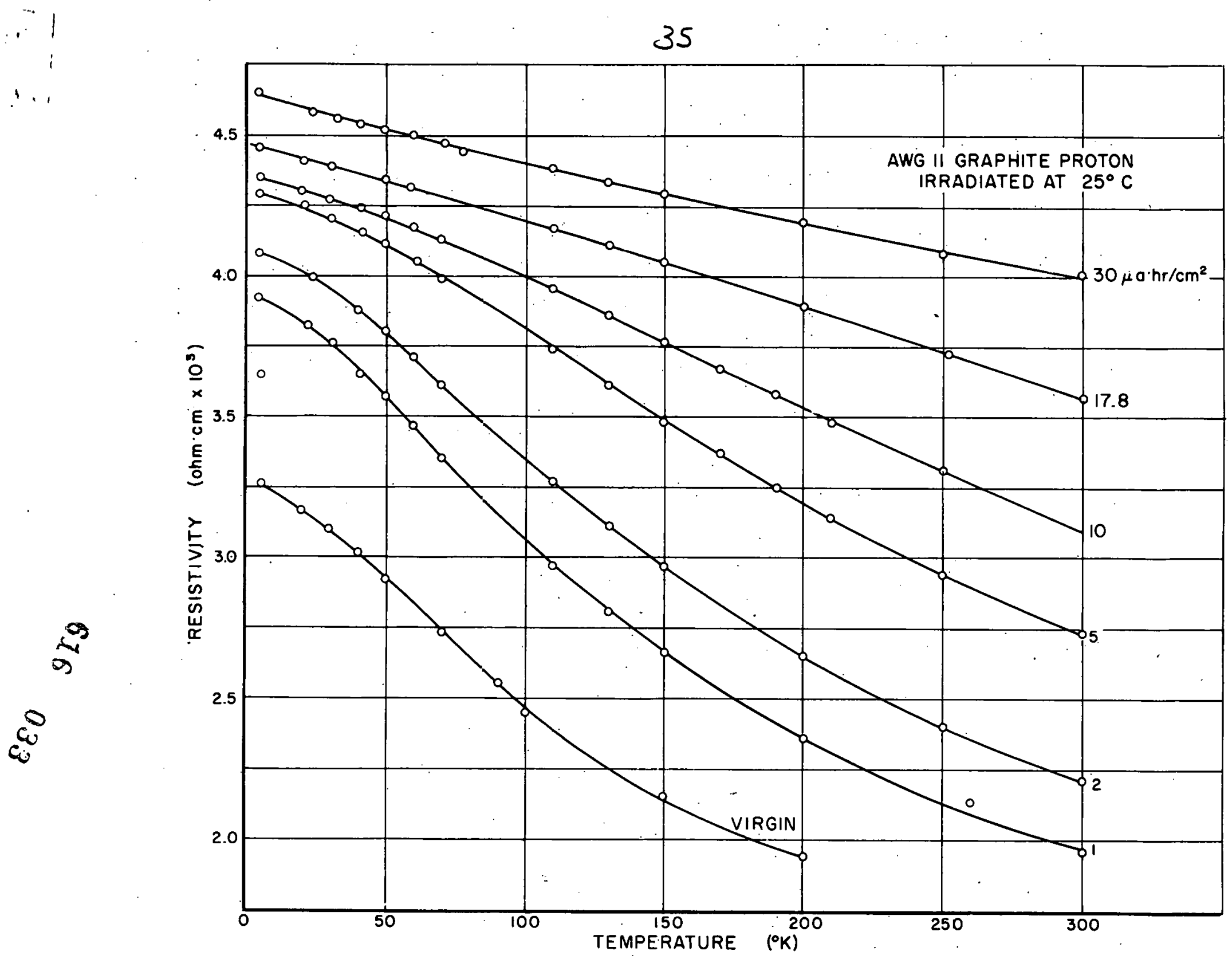

Fig. 19. Resistivity vis Temperature 


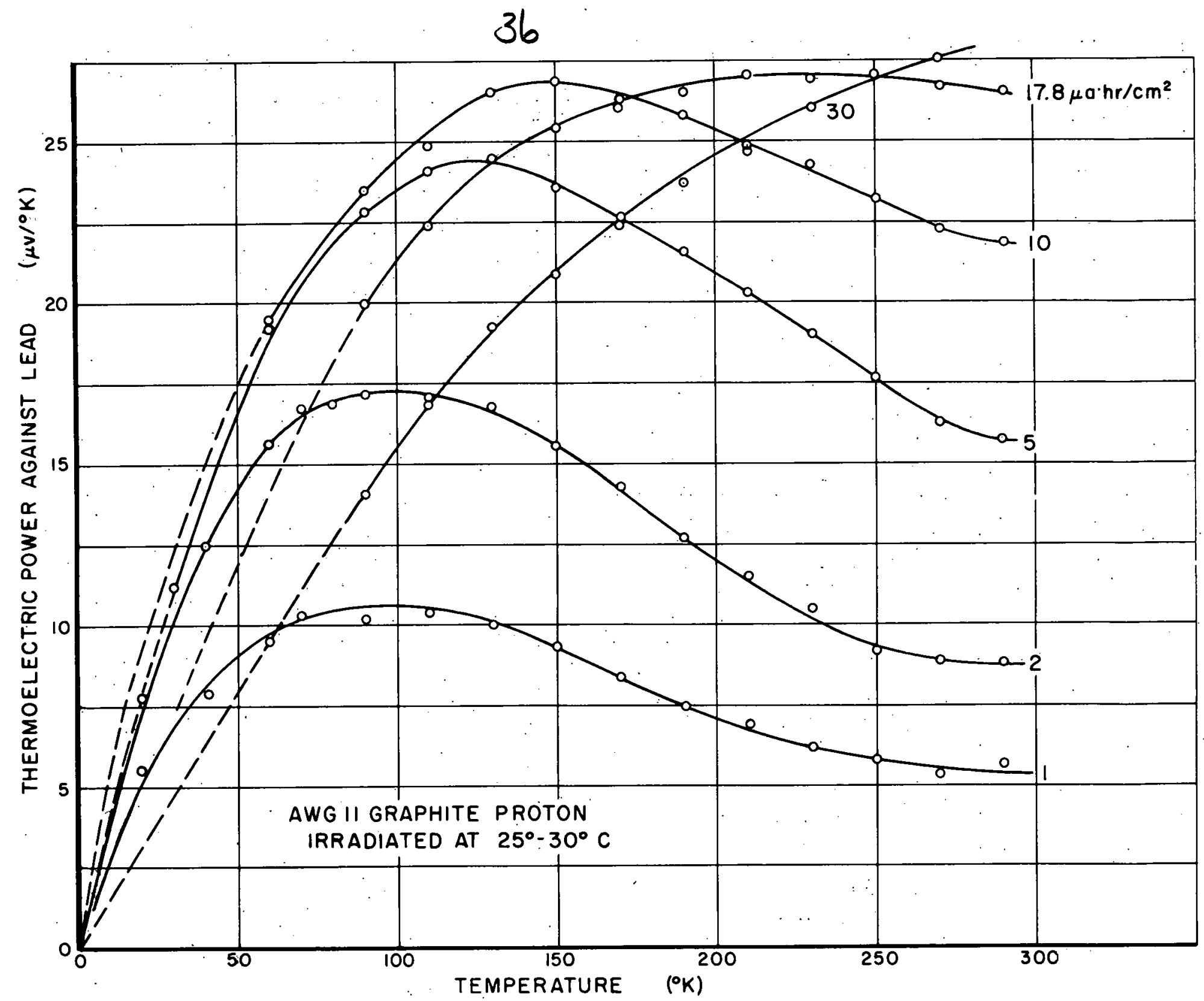

Fig. 20. Thermoelectric Power vs Temperature 


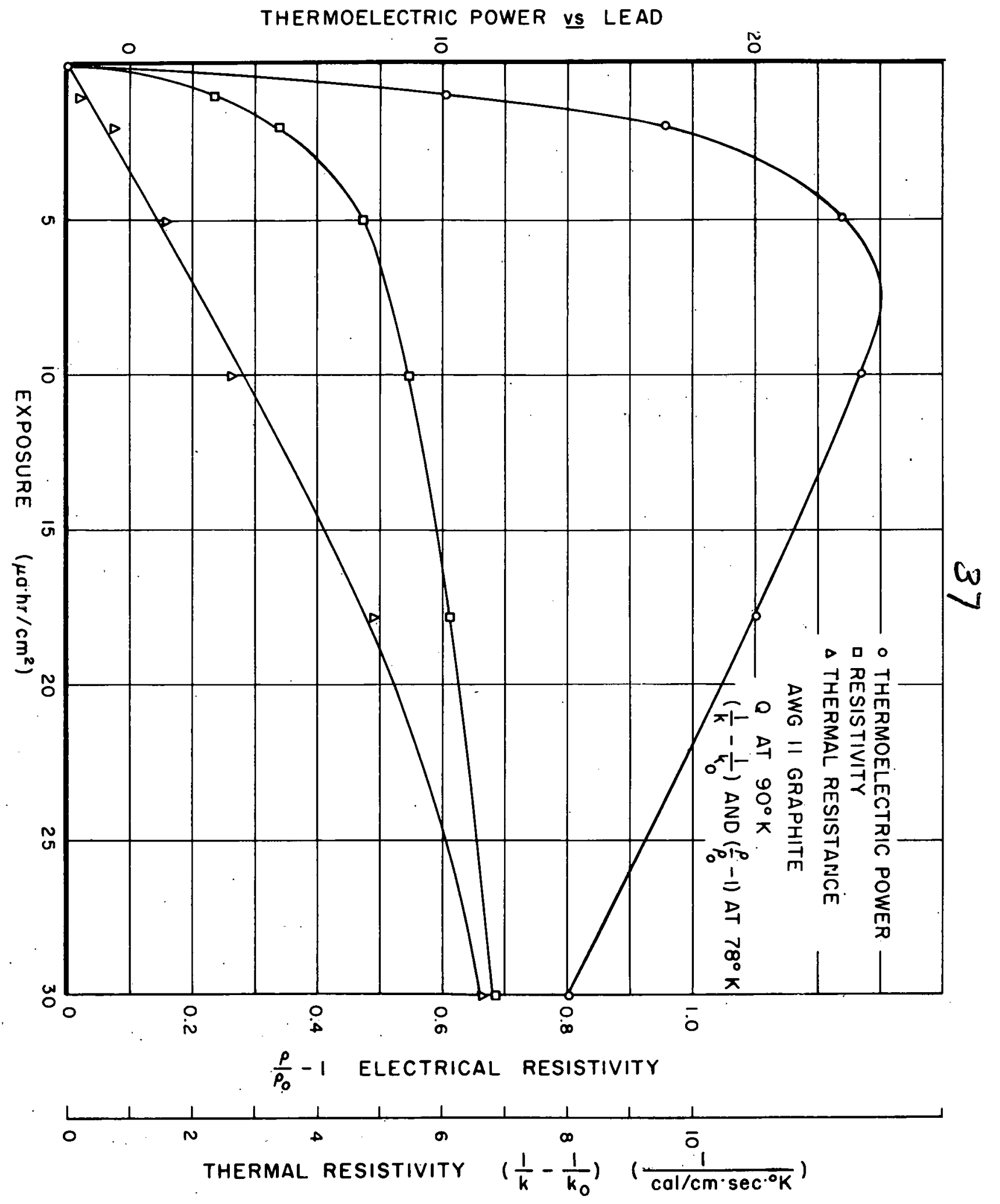

Fig. 21. Thermoelectric Power, Resistivity and Thermal Resistance vs Proton Exposure

$$
\text { 6. } 6
$$


E. In-Place Measurements of Cyclotron-Bombarded Graphite - W. S. Gilbert, D. L. Clark, and J. H. Pepper

The in-place measurements reported preliminarily in the last progress report have been analyzed in greater detail. In addition another irradiation has been carried out at a temperature of $-94^{\circ} \mathrm{C}$. In Figs. 22 and 23 the values for the thermoelectric power, $Q$, and the electrical resistivity, $\rho$ measured at $-180^{\circ} \mathrm{C}$ and $-190^{\circ} \mathrm{C}$, respectively, are compared for irradiations made at $+35^{\circ} \mathrm{C},-94^{\circ} \mathrm{C}$, and $-170^{\circ} \mathrm{C}$.

It can be seen that there are marked differences between the effect of irradiation at room temperature and the effect of irradiation at the low temperatures. However, there is relatively little difference between the results from the two cold irradiations even through there is a difference in the irradiation temperature of some $76^{\circ} \mathrm{C}$. Considerable annealing data have been obtained and will be included in a topical report covering the work.

F. Asymptotic Aging Experiments - R. L. Carter, S. B. Austerman

In the previous progress report experiments were reported showing that annealing of stored energy from irradiated graphite at temperatures from $200^{\circ} \mathrm{C}$ to $475^{\circ} \mathrm{C}$ could be described in terms of a series of first order proces'ses. It was indicated, however, that the observed processes could not be separate and independent. Preliminary calculations have shown that under certain circumstances such behavior may be characteristic of the stored energy released from a process limited by diffusion.

These experiments have been extended to observation of low temperature annealing of graphite irradiated at liquid nitrogen temperature with dẹterons. Quasi-isothermal measurements have been made during annealing at $-78^{\circ} \mathrm{C}$, $-40^{\circ} \mathrm{C}$, and $-3^{\circ} \mathrm{C}$. The energy released during this low temperature annealing appears to amount to at least 20 per cent of the total stored energy expected for the equivalent irradiation. The hope that a single simple process would be identified in this region appears unwarranted. The same type of overlapping, interdependent first-order processes observed at higher temperatures seem to characterize annealing in this range:

In order to determine the temperature regions of active stored energy release, a new variable-temperature annealing apparatus for use between $77^{\circ} \mathrm{K}$ 


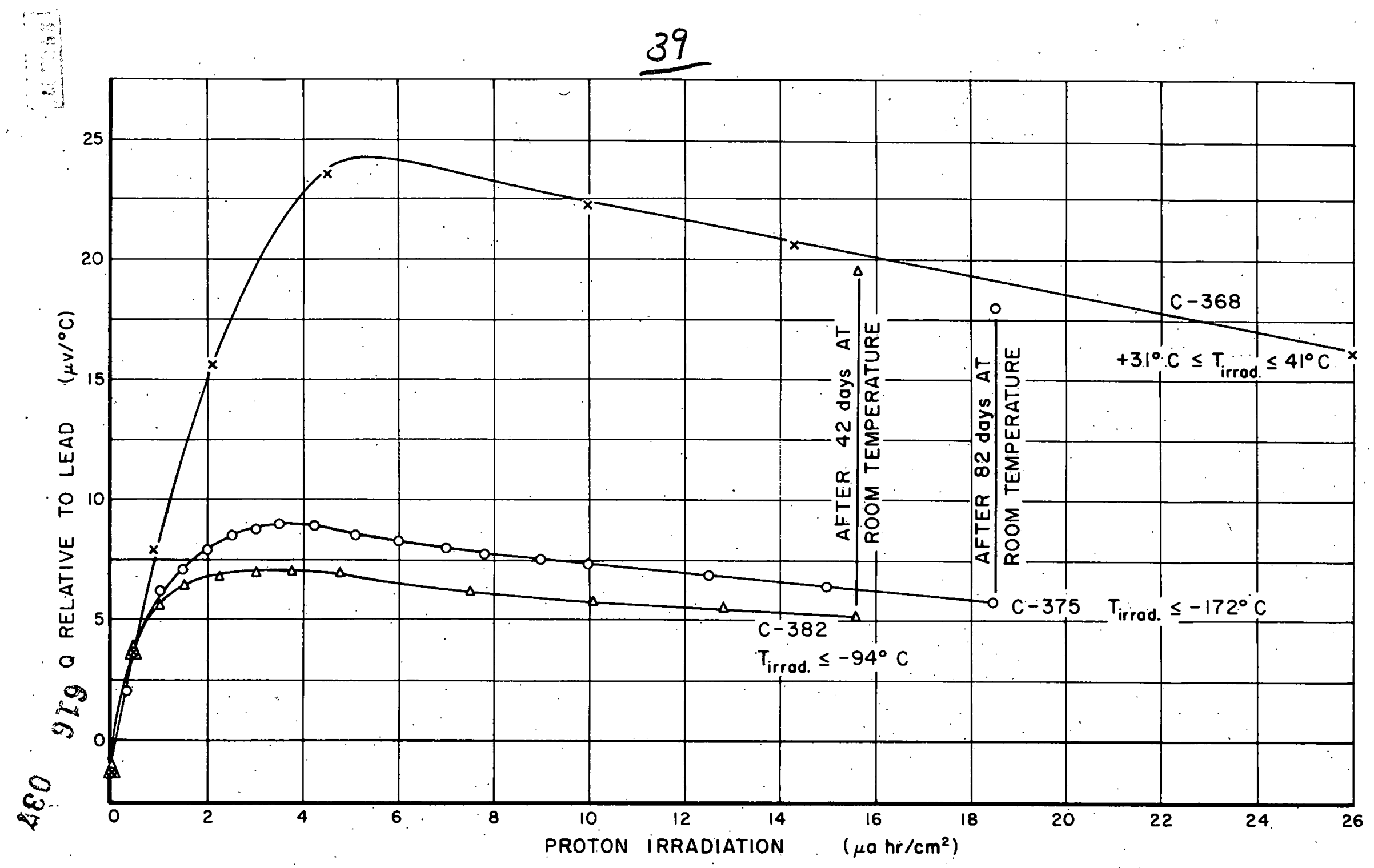

Fig. 22. Q $-185^{\circ} \mathrm{C}$ vs Proton Irradiation for Various Temperatures of Irradiation (AWG 11) 


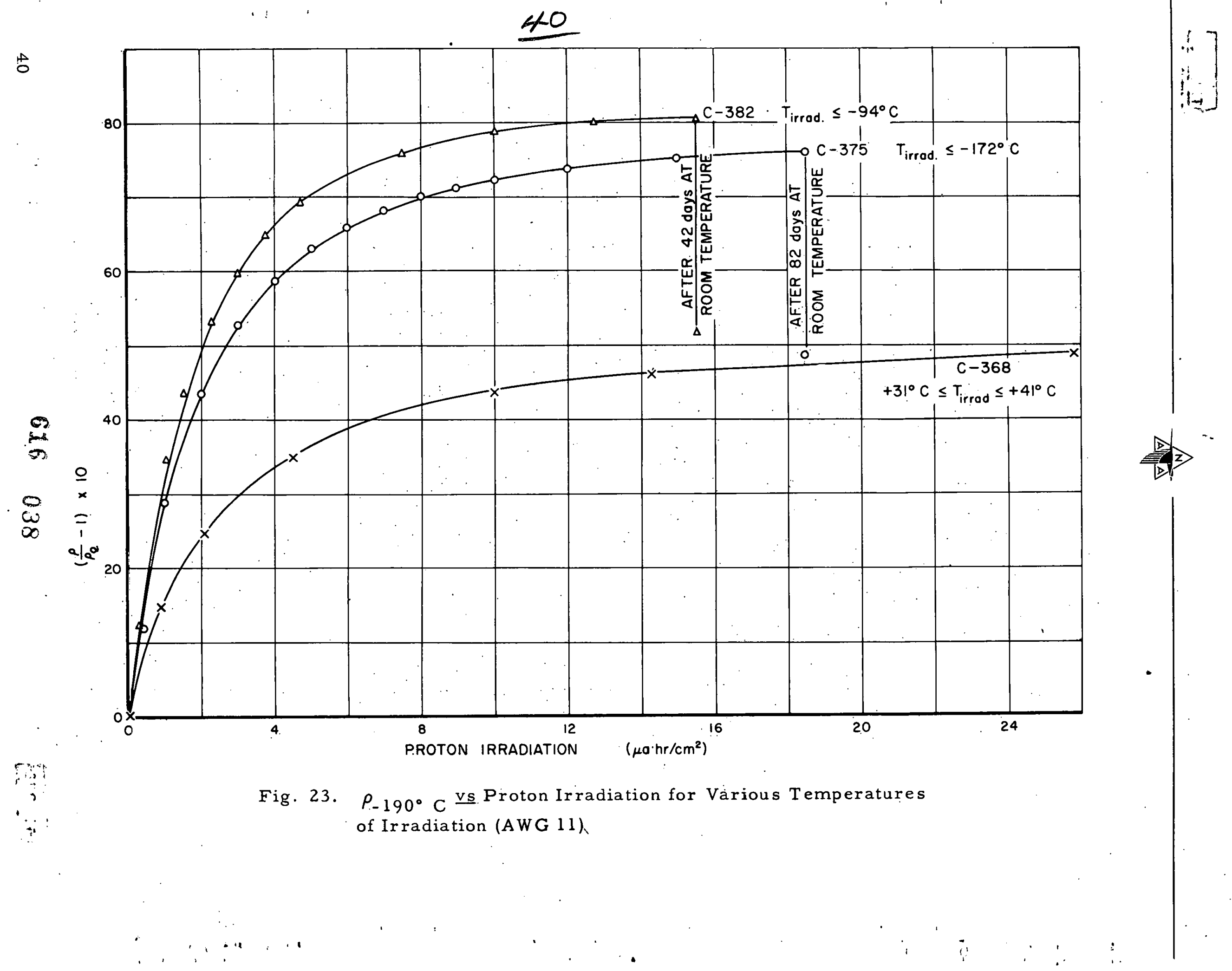




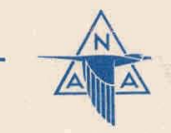

and $100^{\circ} \mathrm{C}$ has been constructed and partially tested. The principle of the new apparatus is quite similar to that constructed for use at higher temperatures; the geometry is shown in Fig. 24. Temperature control of the block is achieved through the use of cooling coils and heater wires wrapped around the block. Thermocouples are installed in the block and on the end of the specimen probe to measure the temperature of the block and the temperature difference between the block and the specimen. The specimens will be no larger than $3 / 16$ inch diameter and $3 / 8$ inch long.

In practice, the specimen will be mounted on the end of the probe in the loading pan which will contain liquid nitrogen. The block will be cooled to nitrogen temperature and the specimen inserted into the annealing cavity. The block will then be heated at some controlled rate; the temperature of an unirradiated specimen will lag that of the block by an amount determined by gaseous heat transfer within the cavity. In the case of an irradiated specimen in the cavity, the temperature lag will be less because of the stored-energy contribution to the heating of the specimen. Determination of the stored energy release will be made by recording the temperature lag during heating for an irradiated specimen, and then again for the same specimen after annealing. The difference in temperature lag for the two runs can then be related to the release of stored energy at increasing temperatures. Although the temperature stability of the block has not been tested, it is anticipated that the apparatus can also be used for isothermal anneals at low temperatures.

The topical report for the isothermal annealing studies of $48 \mathrm{mwd} / \mathrm{ct}$ AGOT-KC graphite has been completed. 


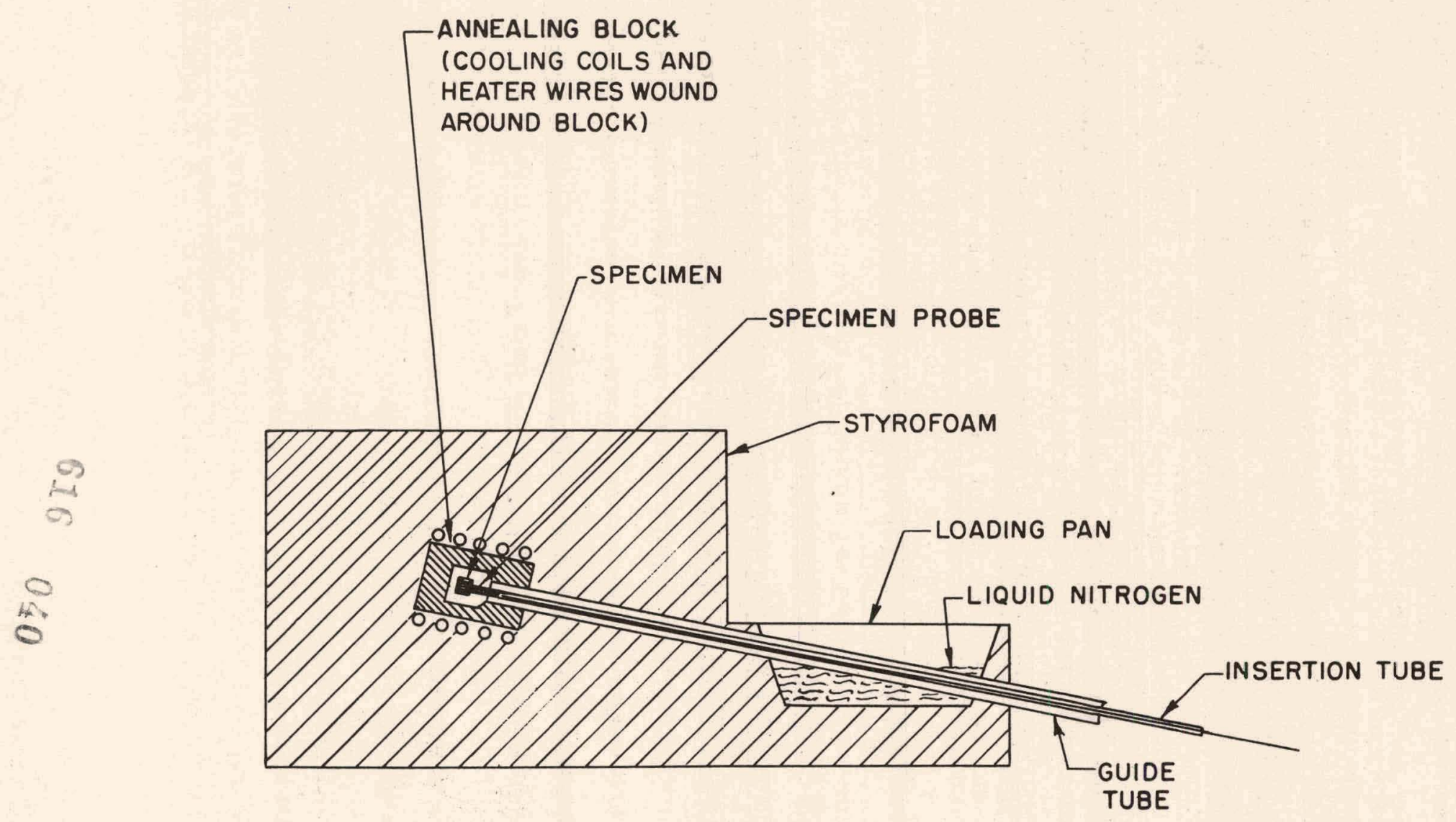

Fig. 24. Stored Energy Apparatus 


\section{METALS}

A. Mechanism of Pore Formation Associated with the Kirkendall Effect

J. A. Brinkman

Following is the abstract of a topical report on the mechanism of pore formation in Kirkendall experiments:

"It is shown that a two-dimensional tensile stress is established in Kirkendall-type diffusion:specimens on the side of the interface suffering a net loss of atoms. In the presence of this stress, voids larger than a critical size will grow by absorbing vacant lattice sites when the concentration of such sites is maintained at its equilibrium value. A mechanism is proposed by which the tensile stress can nucleate voids of this critical size or larger. Thus the proposed mechanism of nucleation and growth of the voids formed in connection with Kirkendall-type diffusion experiments can operate without the existence of an excess concentration of vaćancies." "*

\section{B. Annealing Studies of Cyclotron-Irradiated Thorium - C. J. Meechan}

The investigation of some reactor fuel materials from the standpoint of lattice imperfection is being continued. At present the emphasis is on the roomtemperature annealing state found on annealing iodide-processed thorium which has been irradiated near the liquid-nitrogen temperature. The previous progress-report contained tempering curves for both cold-worked and irradiated thorium; which showed a rapid recovery of the electrical resistance in the vicinity of room temperature. This state has been investigated and the corresponding activation. energy has been determined.

Iodide-processed thorium foils of dimensions 1 inch by 0.40 inch by 0.002 inch were irradiated on the Crocker Laboratory 60-inch Cyclotron at the University of California with $9-\mathrm{Mev}$ protons. The sample temperature was maintained below $-140^{\circ} \mathrm{C}$ at all times during and following the irradiation. Inplace measurements were not made, but comparisons with similar previous irradiations of the same material indicate that a resistivity increase of

Part A of Section II is unclassified.

6. 6 
approximately 50 per cent at the liquid-helium point must have occurred. Final beam profiles have not been examined as yet and consequently the exact amount of irradiation (approximately $35 \mu \mathrm{amp}-\mathrm{hr} / \mathrm{cm}^{2}$ ) is unknown at present.

All resistance measurements following the irradiation were made at the liquid-helium temperature using standard potentiometric methods with Rubicon Type "B" potentiometers: The samples were remounted under liquid nitrogen and then pulse annealed at various temperatures in the range $0^{\circ}-70^{\circ} \mathrm{C}$ in approximately $10^{\circ} \mathrm{C}$ intervals. The pulse times at the annealing temperatures were all 2 minutes in length. The activation energy determinations were made by measuring the ratio of the slopes of the resistance vs annealing time curves at the point where the annealing temperature was changed. With this ratio and the known annealing temperatures the activation energy $E$ can be determined from the following equation:

$$
\frac{E}{k}=\left(\ln \frac{\mathrm{m}_{2}}{\mathrm{~m}_{1}}\right)\left(\frac{\mathrm{T}_{1} \mathrm{~T}_{2}^{2}}{\mathrm{~T}_{2}-\mathrm{T}_{1}}\right)
$$

where $m_{2}$ and $m_{1}$ are the respective slopes of the resistance-time curves at temperatures $T_{2}$ and $T_{1}$, and $k$ is Boltzmann's constant.

In an attempt to make às many determinations as possible for each sample the annealing temperature was changed in the following manner. The first anneal was at $0^{\circ} \mathrm{C}$, the second at $12^{\circ} \mathrm{C}$, the third at $5^{\circ} \mathrm{C}$, the fourth at $15^{\circ} \mathrm{C}$, etc. It was believed that in this manner more determinations of the activation energy could be made because of the efficient use of the damage in a given sample. The-maximum utilization of the samples was of prime importance since probe difficulties eliminated all but two of the samples from the investigation.

In the manner described above, twelve determinations of the activation energy for the room temperature annealing state of proton-irradiated thoriurn were made for the first sample and four determinations were made for the second sample before the probes were lost. The results of this work are shown in Table I. 
$\underline{\text { TABLE I }}$

ACTIVATION ENERGY FOR THE ROOM-TEMPERATURE

ANNEALING STATE IN THORIUM

\begin{tabular}{|c|c|c|c|}
\hline \multicolumn{2}{|c|}{ Sample No. 1} & \multicolumn{2}{|c|}{ Sample No. 2} \\
\hline$\underset{{ }^{\prime} \mathrm{K}}{\text { Temperature Range }}$ & $\begin{array}{l}E \\
e v\end{array}$ & $\underset{\bullet \mathrm{K}}{\text { Temperature Range }}$ & $\begin{array}{l}E \\
\text { ev }\end{array}$ \\
\hline $\mathrm{T}_{1} \quad \mathrm{~T}_{2}$ & & $\mathrm{~T}_{1} \quad \mathrm{~T}_{2}$ & \\
\hline $292.9-307.9$ & 1.14 & $273.7-283.1$ & 0.95 \\
\hline $307.9-295.1$ & 0.95 & $283.1-278.2$ & 0.71 \\
\hline $295.1-307.1$ & 1.24 & $278.2-288.2$ & 1.18 \\
\hline $307.1-298.0$ & 1.15 & $288.2-298.2$ & 1.17 \\
\hline $298.0-313.4$ & 1.48 & & \\
\hline $313.4-323.3$ & 1.21 & & \\
\hline $323.5-333.6$ & 1.21 & & \\
\hline $333.6-326.9$ & 1.09 & & \\
\hline $326.9-338.3$ & 1.28 & & \\
\hline $338.3-331.6$ & 0.99 & & \\
\hline $331.6-340.1$ & 1.18 & & \\
\hline $340.1-348.2$ & 0.84 & & \\
\hline
\end{tabular}

An examination of these results indicates three main features. First, many of the determinations give a value quite close to $1.20 \mathrm{ev}$. Second, all determinations made where $\mathrm{T}_{1}>\mathrm{T}_{2}$, i.e., when the sample is annealed at the high temperature first and then at a lower temperature, are definitely lower than those made where $\mathrm{T}_{1}<\mathrm{T}_{2}$. Finally, the determinations made at the beginning and at the end of the $0^{\circ}$ to $70^{\circ}$. C annealing state are appreciably lower than those determinations made within this temperature range. An average of all determinations of the activation energy where $T_{1}<T_{2}$ yields a value of $1.20 \mathrm{ev}$. On the other hand, an average of all values where $T_{1}>T_{2}$ yields a value of $0.98 \mathrm{ev}$. The average for all the determinations is $1.11 \mathrm{ev}$.

Explanations of the results of this work are still tentative; however; it is believed that this annealing state may be associated with the motion of interstitial atoms in thorium and that the $1.20-\mathrm{ev}$ activation energy is associated with this 
defect. There is at present no explanation of the differences between determinations where $\mathrm{T}_{1}>\mathrm{T}_{2}$ and $\mathrm{T}_{1}<\mathrm{T}_{2}$, and more data are probably needed in order to reach a definite conclusion. *

C. Tensile Properties of Iodide Thorium at Room Temperature and $77^{\circ} \mathrm{K}$

C. E. Dixon

The iodide thorium was received as wire of diameter 0.0395 inch. It was vacuum annealed for 1 hour at $900^{\circ} \mathrm{C}$. The average grain size following the anneal was $0.02 \mathrm{~mm}$. X-ray examination showed some preferred orientation in the $[310]$ direction, and the lattice parameter was $5.0838 \pm 0.003 / \mathrm{A}$.

A gage length of 3 inches was used and the strain rate was $0.0067 \mathrm{inch} / \mathrm{inch} / \mathrm{min}$ during the tests. The data for four specimens are shown in Table II. The elongation at fracture assumes a uniform reduction in area throughout the gage length; however, there was a slight amount of necking near the fracture in each specimen. Yield points of the type observed in Ames thorium were not observed.

TABLE II

TENSILE PROPERTIES

\begin{tabular}{c|c|c|c|c}
\hline \hline Specimen & $\begin{array}{c}\text { Temperature } \\
{ }^{K} \mathrm{~K}\end{array}$ & $\begin{array}{c}\text { Yield Strength } \\
\text { 0.2\% Off set } \\
\text { psi }\end{array}$ & $\begin{array}{c}\text { Ultimate } \\
\text { Strength } \\
\text { psi }\end{array}$ & $\begin{array}{c}\text { Elongation } \\
\text { at Fracture } \\
\%\end{array}$ \\
\hline 5 & 295 & 7,200 & 16,200 & 25 \\
6 & 295 & 6,900 & 16,200 & 28 \\
7 & 77 & 16,000 & $30,100 \dagger$ & 16 \\
8 & 77 & 16,000 & 30,900 & 23 \\
\hline
\end{tabular}

† Broke in grips.

Further tests showed the ultimate tensile strength to increase about 5 per cent upon increasing the strain rate by a factor of 10 . These preliminary studies indicate there is very little qualitative difference between the tensile behavior of iodide thorium at these temperatures from that of the common facecentered-cubic metals. Copper, for example, has about the same ductility and * The material on this page is unclassified, except for the foregoing paragraph. 
slightly higher ultimate strength and yield strength. Copper also exhibits the same type of dependence upon strain rate.

D. Elastic Modulus - H. Dieckamp

Shear-modulus measurements have been completed on all of, the cyclotronirradiated samples. A topical report is being prepared on the effects of cold work and irradiation on the shear modulus of copper.

There has been interest in extending the shear modulus and internal friction measurements to thorium. In addition to the technological interest in thorium there is the fact that it is, like copper, face-centered cubic but has a higher melting point with the resultant likelihood that defects will move at higher temperatures than in the case of copper.

Some unpublished work by E. C. Crittenden; Jr., has indicated that there is considerable difference in the shear-modulus tempering curves for copper that has been recrystallized at $300^{\circ} \mathrm{C}$ in comparison with those for copper that has been recrystallized at $950^{\circ} \mathrm{C}$. It seems that such effects most probably arise from differences in the preferred orientation and/or the grain size. In the light of this information it seemed advisable to initiate the work on thorium by comparing these factors with the known results of copper. The fiber orientation resulting from drawing thorium wire is an almost perfect $[111]$, which is somewhat different from the orientation of copper, which is about 60 per cent [111] and 40 per cent $[100]$ and high-purity aluminum, which has been reported as $[111]+[100]$. Annealing thorium near the recrystallization temperature $\left(700^{\circ} \mathrm{C}\right)$ results in almost complete $[100]$ fiber orientation, which is also the result in copper and aluminum. It is thought that the $[100]$ component in drawn copper and aluminum results from room temperature recrystallization. In the case of copper and aluminum, annealing at temperatures near the melting point destroys the $[100]$ orientation and results in what appears to be a scattered $[322]$ orientation. Since thorium is quite similar to copper and aluminum in its lower temperature behavior, one might expect the same result for thorium. However, we have so far been ansuccessful in attempts to anneal thorium at temperatures above about $1000^{\circ} \mathrm{C}$ due to its extreme chemical activity at these temperatures.<smiles>[Te]</smiles> 
E. Displacement Energy in Metals - H. M. Kenworthy

A slightly different mounting is now being used for the thin metal foils (cf. work reported earlier i ). The foils are electrically insulated from the copper backing plate with a very thin sheet of mica. Only one strip of foil is being mounted now. One end of the foil is shielded from the electron beam and is used as the control sample. The copper blocks used for electrical connection to the samples are smaller. These changes have made the successful mounting of samples much easier. It is now necessary to irradiate with a very low beam current because of the poor heat transfer through the mica, and as a result a complete run to determine the curve of resistivity change as a function of energy requires several days. Because of the demand for statitron time by another project only one run was made on nickel during this qúarter. The run was terminated when the irradiated sample parted, and insufficient points were obtained near the threshold to enable the accurate determination of the displacement energy. The indication from this run is that the displacement energy in nickel is less than $30 \mathrm{ev}$.

F. Miscellaneous Low-Temperature Work - H. Hori

1. Carbon Resistance Thermometer - A sensitive and reproducible carbon resistance thermometer has been designed and built to cover the temperature range from $2^{\circ}$ to $25^{\circ} \mathrm{K}$. Resistance measurements were made by monitoring the current and measuring the IR drop across the resistor: Heating effects due to power input were held to a minimum by using a current of $1.0 \times 10^{-4}$ amps. The thermometer has not been calibrated to date; however, tentative plans are to have it calibrated by the National Bureau of Standards. Its reproducibility has been measured at the boiling point of helium $\left(4.2^{\circ} \mathrm{K}\right)$ to within $\pm 0.01^{\circ} \mathrm{K}$ over a period of 2 weeks.

2. Liquefaction of Hydrogen - A heat exchanger for liquefying small quantities of hydrogen using liquid helium as the refrigerant has been designed and built. In the most successful run the liquefaction rate was increased from 0.5 liters/hr to 1.2 liters/hr. The ratio of liquid helium consumed to liquid hydrogen produced dropped from 25 to 19.

3. Temperatures Below $4.2^{\circ} \mathrm{K}$ - A specially designed dewar flask has been built to achieve reference-temperature baths below $4.2^{\circ} \mathrm{K}$. The dewar consists of three concentric containers joined at the top. The dewar is all pyrex glass with the exception of the lower end of the innermost container, which 


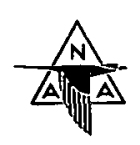

is a copper can sealed to glass. The copper can is used to insure good heat transfer. The second chamber is sealed except for two openings which are for filling and pumping. The outer chamber is evacuated and sealed. The center is partially filled, and the second chamber is completely filled with liquid helium. The second chamber is pumped with a high capacity fore-pump thereby reducing the vapor pressure of the liquid helium and consequently lowering the temperature. Measurements taken in the center indicated temperatures as low as $2.2^{\circ} \mathrm{K}$.

\section{INSULATORS}

A. Mechanism of the Additive Coloring Reaction - D. R. Westervelt, V. Martin

In the previous progress report a summary was given of a forthcoming report on the reaction between the colloidal particles of alkali metal and an alkali-halide crystal in which the particles are embedded. Results obtained earlier had suggested that the thermal transformation of color centers in the alkali halides occurs in a two-step process, in which F-centers first are transformed into a new intermediate center distinguished by a reproducible characteristic peak wavelength $(740 \mathrm{~m} \mu$ in $\mathrm{KCl})$, and these intermediate centers subsequently coagulate into minute colloidally dispersed particles of alkali metal. The principal effort during this quarter has been directed toward answering several fundamental questions raised in the topical report concerning the mechanism of the reaction between the alkali metal particles and the alkali. halide lattice. The theory of this reaction applies both in the case where the particles are contained within the alkali halide crystal and in the case of the additive coloring process in which the metal reservoir is external to the crystal being colored.

One of these questions concerns the reversibility of the reaction. In a paper ${ }^{21}$ which the writer obtained after the work on the report given in Ref. was nearly completed, experimental results were described which tended to invalidate the entire treatment of the problem by statistical methods for they indicated that the additive coloring process actually was irreversible. All of the existing theoretical treatments of this problem are based on the assumption of reversibility, so the experiments described in Ref. 21. were repeated in order to test their remarkable results. The present experiments unambiguously 
confirmed the reversibility of the additive coloring reaction in $\mathrm{KCl}$ at temperatures between $500^{\circ}$ and $600^{\circ} \mathrm{C}$. A crystal colored at $575^{\circ} \mathrm{C}$ contained three times the F-center concentration of one colored at $525^{\circ} \mathrm{C}$. When another crystal colored at the higher temperature subsequently was removed from the high-temperature oven and placed in the lower-temperature oven for a period equal to that in which the crystals colored at $525^{\circ} \mathrm{C}$ had been brought to equilibrium, the resulting $F$-center concentration did not differ from that in the crystals colored at $525^{\circ} \mathrm{C}$ by more than 10 per cent, which is about the limit of accuracy imposed by the small concentrations of long wave length bands of unknown oscillator strength on the optical determination. A determination of the concentration of excess alkali, which will be discussed further below, confirmed this result. The principal evidence of irreversibility, namely, failure to approach the equilibrium concentration from either direction, thus was not substantiated by our experiments.

Further evidence for irreversibility was asserted in Ref. 21 to follow from an observation that similar concentrations of color centers are obtained in $\mathrm{KCl}$, regardless of the alkali metal vapor used in the coloring process. That this result is not inconsistent with the equilibrium theory is easily shown; nevertheless, the experiment was repeated by coloring $\mathrm{KCl}$ both in $\mathrm{Na}$ and in $\mathrm{K}$ vapor at a temperature of $725^{\circ} \mathrm{C}$. The evacuated stainless-steel capsules containing the $\mathrm{KCl}$ were not quenched in water upon removal from the furnaces, a procedure now followed; and it was subsequently observed that a considerable aggregation into colloidal particles had occurred in the $\mathrm{K}$-colored crystal during the process of cooling in air. These particles were so large that their presence was easily detected in the bright field of an ordinary microscope, and under dark-field illumination they were clearly visible. A less prominent colloidal dispersion was observed in the crystals colored with $\mathrm{Na}$. These two groups of crystals showed optical peculiarities which will be discussed in the following section. An optical determination of the F-center concentration yielded results agreeing within 50 per cent in the two kinds of crystal, but due to the presence of colloidal metal recourse was necessary to chemical methods in order to determine the total concentration of excess metal. Because these experiments, carried out by $M$. Shideler and L. Silverman of the Analytical Chemistry Unit and representing a significant advance in the application of potentiometric and colorimetric methods to slightly non-stoichiometric materials, are not yet complete, a complete discussion of them will be deferred to a subsequent 
progress report. In the case under discussion, a tentative value for the ratio found for the excess metal concentration in the crystals colored with $K$ and $\mathrm{Na}$ at $725^{\circ} \mathrm{C}$ is about 2.3 , which is of the order of magnitude of the value predicted by the equilibrium theory. These experiments are being repeated with rapid quenching of the capsule to eliminate changes in concentration during cooling. It is hoped that the present potentiometric analyses will provide a new experimental determination of the oscillator strength of the F-center in $\mathrm{KCl}$.

In a further application of the method it has been shown beyond any doubt that crystals of $\mathrm{KCl}$ and $\mathrm{NaCl}$ heavily bombarded with $\mathrm{l}-\mathrm{Mev}$ electrons or with fast neutrons so that $F$-center concentrations well in excess of $10^{18} \mathrm{~cm}^{-3}$ are produced (the approximate limit beyond which the concentration cannot be measured optically due to the impossibility of cleaving thin enough specimens) remain stoichiometric within a limit of less than 1 per cent of the F-center concentration produced by bombardment. Thus the photochemical process and the radiation damage produced by fast neutrons do not involve photolytic decomposition with preferential liberation of one component of the crystal

\section{B. New Optical Effects in Additively Colored Crystals - D. R. Westervelt, V. Martin}

Analysis of pieces cleaved from the potassium chloride crystal colored in sodium vapor demonstrated that sodium was not present in the interior of the crystal, a result which will be discussed in a subsequent report. In view of the absence of $\mathrm{Na}$ within the $\mathrm{Na}$-colored crystal, the absorption spectrum shown in Fig. 25 is rather surprising. In the region of the $\mathrm{N}$-band in $\mathrm{KCl}$ appears an entirely new band found only in $\mathrm{KCl}$ colored by $\mathrm{Na}$ and never in $\mathrm{KCl}$ colored by $\mathrm{K}$ (cf. the $\mathrm{N}$-band in Fig. 26). The new band was found in all batches of $\mathrm{Na}$-colored $\mathrm{KCl}$, the blank materials for which were purposely chosen from different Harshaw lots of $\mathrm{KCl}$, and cannot be attributed to experimental aberrations of any sort. The nature of this band is not clear, although it occurs in a region in which $\mathrm{N}$-band structure in radiation-damaged crystals occurs.

One additional observation deserves mention. In Fig. 26 is shown the spectrum of one of the $\mathrm{KCl}$ crystals colored with $\mathrm{K}$ and containing very large colloidal particles. It will be observed that the normal $F-, R-$, and $M$-center structure is superimposed on a broad absorption background which is quite different in character from the sharp colloidal bands discussed previously but 

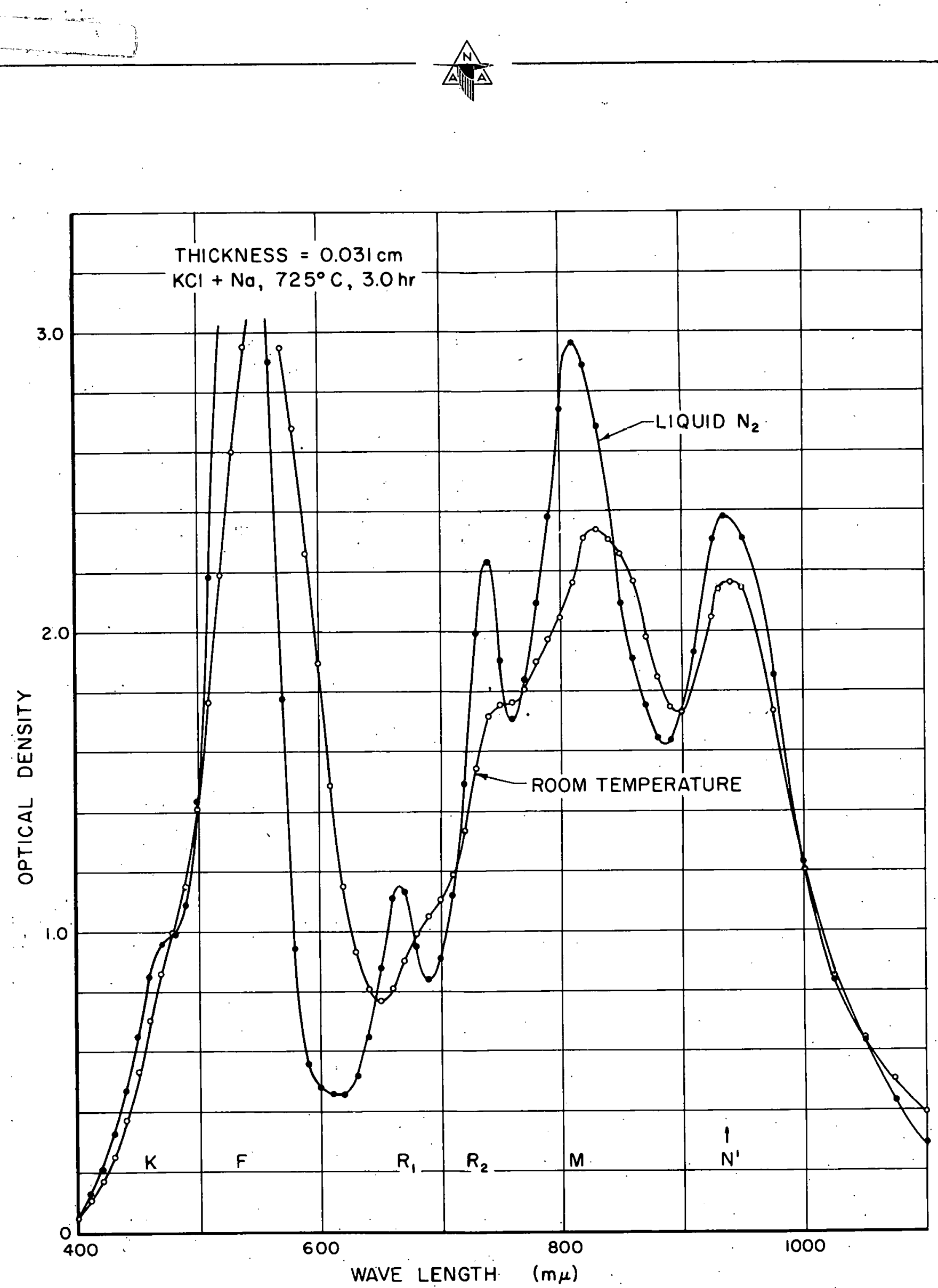

Fig. 25. Absorption of KCl Colored in Na Vapor 
$\frac{\widehat{A}}{\Delta \| \hat{A}}$

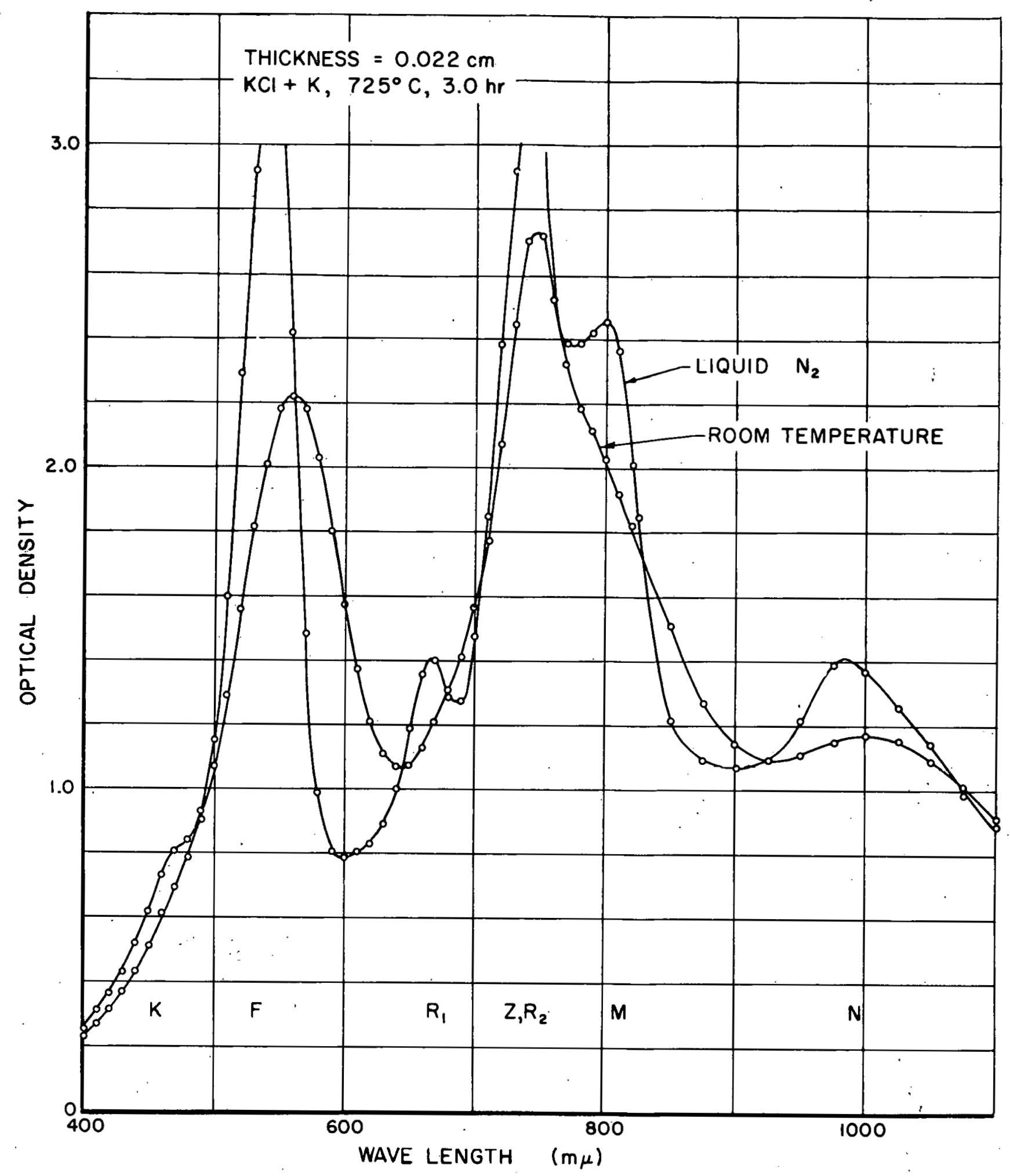

Fig. 26. Absorption of Additively Colored KCl Containing Microscopically Observable Colloidal Particles 
is in accordance with what one might expect on the basis of the theoretical curves obtained by Savostianowa. ${ }^{22}$ Particles of the size involved here probably are several hundred microns in size instead of being in the sub-microscopic range as in the case of the particles in the samples which yield the sharp colloidal bands. *

\section{IRRADIATIONS}

\section{A. Cyclotron Operation and Development}

1. Operation - A. Andrew - During this quarter the 60-inch cyclotron at Crocker Laboratory was used a total of 88 hours for radiation-damage studies. Irradiations were made in order to determine the effect of radiation on the following properties:

1. Thermoelectric power of graphite

2. Stored energy of graphite

3. Thermal conductivity of graphite

4. Ir radiation effects in thorium

The cyclotron was shut down for modification late in April. Since this time, much of the effort has been devoted to revamping the equipment.

2. Irradiation Effects in Impregnated Graphite - A. Andrew, F. E. Faris, and B. T. Harwick - The comparison of irradiation damage due to deuterons and to fission fragments in C-18 graphite has been completed, and a topical report covering the work is being prepared. Consequently details will not be given here. An extension of Brown's work, ${ }^{23}$ taking into account the effect of lattice oscillations, predicts resistivity increases of 17 per cent and 12 per cent in two cases of a combination of fission-fragment and deuteron damage. The measured increases were 14 per cent and 7 per cent, respectively. The agreement between theory and experiment is considered to be satisfactory, particularly in view of the approximations used in the calculations.

3. Mass Transfer of Radioactivity - L. E. Glasgow - A preliminary design study of an experiment to check the calculations of the number of atoms knocked

*The foregoing is unclassified. $\quad 616 \quad 052$ 
out of an iron foil by alpha particle bombardment has been completed. The calculated minimum amount of activity required to do the experiment is $0.2 \mathrm{mc}$. The minimum specific activity required is 0.3 curies per gram. $\mathrm{Fe}^{55}$ is available in this concentration. The experimental arrangement would consist of an iron foil containing electroplated radioactive iron and a second foil arranged to collect the knocked-out atoms. The $\gamma$ activity transferred would be used as a measure of the atoms transferred.

A preliminary design for a pumped sodium stainless-steel corrosion loop has been made. The loop would consist of an irradiation cell containing a radioactive stainless steel foil, an electro-magnetic pump which would use the cyclotron field, and a 12-inch rectangular loop of 1/4-inch stainless steel tubing. The purpose of the loop would be to measure the sum of the activity transferred due to the solubility of stainless steel in sodium and the knocked-out atoms. In this particular design the $\mathrm{CO}^{60} \gamma$ activity gained by the sodium would be measured at the unirradiated end of the loop. The increase of $\gamma$ activity would be taken as a measure of the mass transfer. Since the loop would not have to be opened for $y$ counting, the irradiation and control runs could be made alternately with the same sample. The effect of irradiation would then be inferred from any difference in the rate of $\gamma$ activity increase with time.

B. Statitron Operation and Development - H. M. Kenworthy

The irradiation time on the statitron for the quarter has been divided as follows:

1. 350 houre of irradiation for organic-coolant studies

2. 35 hours of irradiation for the nickel displacement-energy experiment.

3. 8 hours of irradiation for the calibration. of the energy transferred in several different target cells designed for radiation-chemistry studies.

Sulfur hexafluoride gas has been tried in the machine for insulating purposes with very promising results. An insulating gas circulating system with a drying chamber has been designed and is now under construction. This circulating system will soon be installed.

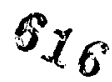<smiles>[Se]=[Pd]</smiles> 
C. In-Pile Experiments - D. J. Klein, R. E. Durand, and R. R. Eggleston

The second thimble for the measurement of the thermal conductivity of graphite under reactor irradiation (NAA-3 experiment at the MTR) has been completed and shipped to the reactor site. Arrangements are under way for :removal of the samples from the first thimble, which was irradiated during the last quarter. Tentative results of the first run are reported in NAA-SR-1049. ${ }^{24}$ 


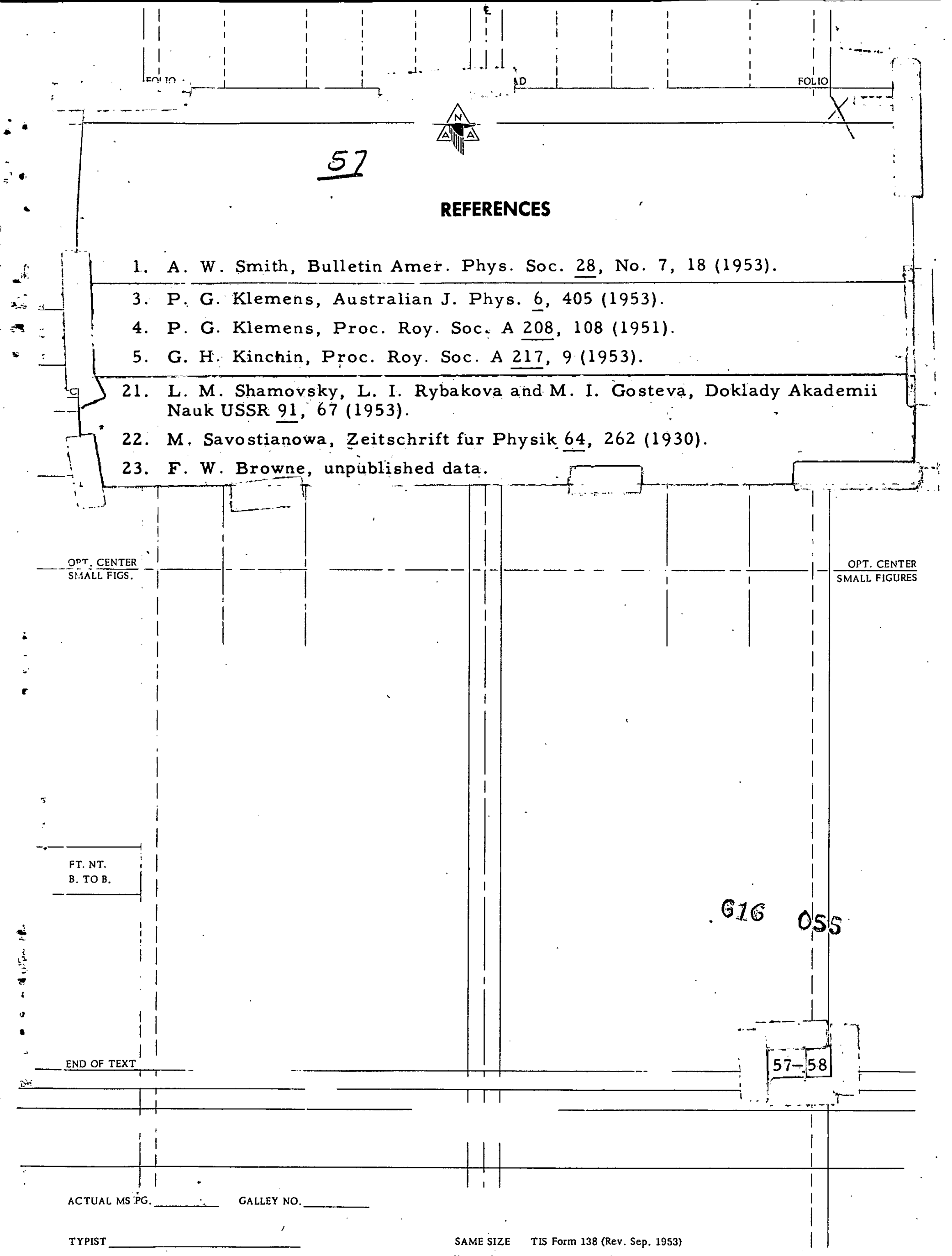




\section{THIS PAGE}

\section{WAS INTENTIONALLY}

\section{LEFT BLANK}

